\title{
Razão ou sensibilidade? Decidindo casos sobre liberdade de expressão: lições do cenário norte-americano*
}

\section{Sense or sensibility? Deciding on freedom of speech: lessons from the U.S. law}

\section{Resumo}

O presente trabalho propõe que as decisões judiciais envolvendo liberdade de expressão devem ser orientadas por meio de parâmetros e critérios previamente definidos e que possam guiar o intérprete judicial ao aplicar a ponderação e o exame de proporcionalidade nos conflitos e restrições à liberdade de expressão. Para tal, o trabalho expõe os conceitos de minimalismo e maximalismo nas decisões judiciais, sustentando que decisões maximalistas nesse cenário podem ajudar a criar os parâmetros necessários, bem como percorrer os parâmetros construídos pela Suprema Corte dos Estados Unidos, que representa, no direito comparado, o modelo mais complexo para avaliação da liberdade de expressão. Pretende-se, assim, sustentar que a criação de parâmetros e critérios possam, além de trazer segurança e previsibilidade à atividade jurisdicional, garantir, na prática, o caráter preferencial da liberdade de expressão.

Palavras-chave: Liberdade de expressão. Posição preferencial. Ponderação. Proporcionalidade. Primeira Emenda.

\begin{abstract}
The paper proposes that judicial decisions on freedom of speech should be guided by predefined parameters and rules that could guide the judge on the exam of balancing and proportionality in these cases. To this end, the paper assesses the concepts of minimalism and maximalism on judicial decisions, arguing that maximalist decisions on this context might help the creation of rules and standards. It also exposes the standards built by the U.S. Supreme Court, which can be identified, in the comparative law, as the most intricate model on freedom of speech cases. The aim, therefore, is to hold that the creation of rules and standards can, besides of bringing certainty and predictability to the judicial activity, guarantee the preferred position of the fundamental right of freedom of speech.
\end{abstract}

Keywords: Freedom of speech. Preferred position. Balancing. Proportionality. First Amendment. 


\section{Introdução}

O Tribunal de Justiça do Estado do Rio de Janeiro ${ }^{2}$ decide mensalmente diversos e diferentes casos envolvendo liberdade de expressão - em quase sua totalidade, hipóteses que tratam do conflito entre liberdade de expressão e direitos da personalidade. Em determinada ocasião, em um período de menos de 24 horas, órgãos julgadores distintos do Tribunal decidiram que: (i) o prefeito de uma cidade deve ser indenizado, em R \$ 20 mil, por ofensas praticadas por um cidadão em sua página pessoal no Facebook, referentes a uma investigação de corrupção do Ministério Público, em que este acusa o prefeito de ter lhe oferecido dinheiro ${ }^{3}$; (ii) o prefeito de uma cidade não tem direito de indenização em face à veiculação de publicação em jornal supostamente ofensiva à sua honra e imagem, com acusações como "criminoso" e de realização de assédio sexual ${ }^{4}$. Ambos os casos identificam o conflito constitucional entre a liberdade de expressão e de imprensa e o direito à imagem, honra reputação e privacidade, embora, analisando as circunstâncias dos casos concretos (muito similares entre si), tenham alcançado conclusões opostas.

A lógica por trás desses casos - e de muitos outros que poderiam ser utilizados como exemplo - reside no fato de que cabe ao julgador avaliar as circunstâncias particulares e realizar a concordância dos preceitos constitucionais em conflito. Em quase todas as hipóteses, há a explícita referência à "ponderação" e muitas vezes à "proporcionalidade", em que os julgadores decidem, à luz do caso concreto, o conflito entre as normas constitucionais em jogo. Dada a grande abstração e generalidade dos valores que estão em colisão, não espanta que uma breve análise dos casos julgados no Brasil revele uma grande dose de casuísmo e liberdade do julgador, que pode optar por qualquer dos direitos fundamentais em conflito sob

2 A escolha do Tribunal é apenas exemplificativa e não obedece a qualquer critério metodológico específico, senão o fato de ser um dos maiores tribunais do país em volume de processos julgados, além de ter uma ferramenta de pesquisa de jurisprudência atualizada.

3 RIO DE JANEIRO. Tribunal de Justiça do Rio de Janeiro. Julgado $1^{\circ}$ de outubro de 2014, Apelação 001111388.2012.8.19.0045, 6ª Câmara Cível, Rel. Des. Benedito Abicair.

4 RIO DE JANEIRO. Tribunal de Justiça do Rio de Janeiro. Julgado em 30 de setembro de 2014, 000215466.2009.8.19.0035, 9a Câmara Cível, Rel. Des. Roberto de Abreu e Silva. a premissa de, ao utilizar a técnica da ponderação, estar realizando a justiça do caso concreto.

Um dos episódios mais dramáticos e complexos do direito brasileiro nos últimos anos tornou-se o ajuizamento de ações judiciais de pessoas que requerem do Poder Público o acesso a medicamentos ou tratamentos de saúde - muitas vezes caros e raros - que representam a última esperança de sua sobrevivência. O conflito, corriqueiro nas varas e plantões judiciários por todo o país, envolve, de um lado, o acesso universal à saúde garantida pela Constituição Federal a todos os cidadãos e, de outro, os recursos limitados de que dispõe o Estado para arcar com tais demandas. Os casos impõem ao Judiciário escolhas trágicas, com a eventual prevalência de um direito individual reconhecido em juízo em detrimento de outras pessoas e de políticas públicas abrangentes. Naturalmente, trata-se de situações que, individualmente, impressionam a qualquer magistrado preocupado com a justiça e a manutenção da vida e dignidade daqueles que recorrem ao Judiciário. Desde o vertiginoso aumento do número de ações dessa natureza, o Judiciário ${ }^{5}$ e a doutrina ${ }^{6}$ têm se dedicado à intricada tarefa de construir parâmetros e premissas para a avaliação de casos, orientando o intérprete por meio de critérios mais universalizáveis e gerais que possam transcender as paixões individuais de cada caso.

Com as devidas proporções - o direito à saúde é uma das expectativas mais elementares e sagradas de cada ser humano -, tal dilema não se restringe aos direitos sociais e ao direito à saúde, mas também pode ser encontrado em outros conflitos envolvendo direitos fundamentais. Como identificado acima, o presente estudo destina-se à avaliação dessas premissas nos conflitos que envolvem a liberdade de expressão. Também aqui, apesar de um default de ampla liberdade assegurada pela Constituição Federal, é sabido que a livre expressão poderá sofrer restrições em prol de outros direitos fundamentais ou interesses estatais. Os casos de liberdade de expressão submetidos ao Judiciário brasileiro não raro envolvem

5 Destaque-se a decisão do Supremo Tribunal Federal que busca estabelecer parâmetros para demandas que requeiram a concessão de medicamentos pelo Estado (STF, DJ 30 abr. 2010, AgR na STA 278/CE, Rel. Min. Gilmar Mendes).

6 V., apenas a título de exemplo, SOUZA NETO, Cláudio Pereira de. A justiciabilidade dos direitos sociais: críticas e parâmetros. In: SOUZA NETO, Cláudio Pereira de; SARMENTO, Daniel. Direitos sociais: fundamentos, judicialização e direitos sociais em espécie. Rio de Janeiro: Lumen Juris, 2010. p. 515. 
expressa referência ao compromisso constitucional com a liberdade de expressão, mas muitas vezes terminam com o comprometimento desta em favor de outros direitos individuais ou estatais que estejam em jogo ${ }^{7}$. O cenário é um discurso - judiciário e doutrinário - desencontrado dos seus resultados: ao mesmo tempo em que se reconhece a importância da garantia da liberdade de expressão no nosso regime constitucional e democrático, a prática judiciária envolve muitas vezes a sua flexibilização em prol de outros valores.

Nessas hipóteses, é natural e esperado que as premissas do caso concreto impressionem e convençam os juízes. De modo geral, as pessoas que ingressam com ações no Judiciário (com todos os custos financeiros e emocionais envolvidos) requerendo sua proteção face à liberdade de expressão ou de imprensa não o fazem por razões banais ou frivolidades. Trata-se de casos em que os indivíduos realmente buscam a reparação por ofensas que os humilharam, mentiras que destruíram sua reputação, invasões de privacidade que transgrediram suas vidas. O juiz, como um ser inserido em seu mundo e realidade, não raro se mostrará sensível ao drama vivenciado pelo autor em cada caso. O Judiciário, naturalmente, está preocupado com a justiça do caso concreto: determinar a retirada de determinada publicação aqui, ou conceder uma indenização ali não arruinará a livre expressão de ideias no direito brasileiro. Quando, porém, essa tendência torna-se a regra, os efeitos à liberdade de expressão, em larga escala, são visíveis - e não é por acaso que a

V., a título de exemplo, análise empírica no âmbito da jurisprudência do Superior Tribunal de Justiça conduzido por Paula Chueke Rabacov sob a orientação do professor da PUC/RJ Fábio Leite, que apurou: "Por um lado, os ministros do Superior Tribunal de Justiça frequentemente clamam e exaltam a importância que esse direito [liberdade de expressão] ocupa na ordenação brasileira [...]. Mas, por outro lado, os resultados apontam em sentido diverso: A assinalada importância parece ficar tão somente no plano ideológico, retórico, porquanto ainda que em variadas decisões seja evocada a sua relevância, em nenhuma delas justificam-na, explicam essa importância, em nenhum se trouxe exemplos que comprovassem essa premissa, e em muito poucos deles se decidiu de forma a prestigiar essa posição. Ademais, os números encontrados certamente contrariam a assertiva de que as limitações à liberdade de informação devem importar em exceção, afinal, elas, na verdade, preponderam em pelo menos $70 \%$ dos casos" (Liberdade de expressão e direitos da personalidade na jurisprudência do STJ. Disponível em: RIO DE JANEIRO. Tribunal de Justiça do Rio de Janeiro. Disponível em: <http://www.puc-rio.br/ pibic/relatorio_resumo2012/relatorios_pdf/ccs/DIR/JUR-Paula\%20Chueke\%20Rabacov.pdf>. Acesso em: 22 mar. 2015. liberdade de expressão continua sendo sempre um tema tão em voga no Brasil.

O que o intérprete que vai julgar casos envolvendo a liberdade de expressão precisa é de razão ou sensibilida$d e^{8}$ ? Um aparato teórico forte e inabalável para orientar o magistrado, transcendendo os dilemas dos casos individuais - aqui identificada como uma maior racionalização no processo decisório? Ou a flexibilidade e liberdade de permitir ao julgador a verificação das circunstâncias concretas dos casos que lhe são submetidos, permitindo decisões mais justas e adaptadas aos dilemas do mundo real - aqui identificada como a sensibilidade?

A tese do presente trabalho é de que, também nessa seara, parece ser necessário observar a figura maior: recorrer a padrões, parâmetros e premissas que possam orientar o intérprete judicial a decidir os casos que lhe são submetidos, transcendendo as idiossincrasias e dramas da justiça individual para buscar soluções mais ou menos universalizáveis. A premissa básica que orienta o estudo é de que o ordenamento jurídico brasileiro confere uma posição de destaque à liberdade de expressão - frequentemente referida, no direito comparado, como a posição preferencial da liberdade de expressão ${ }^{9}$. A jurisprudência brasileira, inclusive do Supremo Tribunal Federal, parece ter alcançado a primeira parte dessa orientação, com o reconhecimento teórico e abstrato das razões que justificam uma garantia reforçada da liberdade de expressão ${ }^{10}$.

A referência, naturalmente, é do clássico literário da escritora britânica Jane Austen, Razão e Sensibilidade.

9 A posição preferencial é reconhecida, por exemplo, pela Suprema Corte dos Estados Unidos, pela Corte Europeia de Direitos Humanos, pela House of Lords britânica, e, no Brasil, seria corolário na jurisprudência do Supremo Tribunal Federal na ADPF 130 (não-recepção da Lei de Imprensa). Sobre o tema, v. CHEQUER, Claudio. A liberdade de expressão como direito fundamental preferencial prima facie: análise crítica e proposta de revisão ao padrão jurisprudencial brasileiro. Rio de Janeiro: Lumen Juris, 2011; SCHREIBER, Simone. Liberdade de expressão: justificativa teórica e a doutrina da posição preferencial no ordenamento jurídico. In: BARROSO, Luís Roberto (Org.). A reconstrução democrática do direito público no Brasil. Rio de Janeiro: Renovar, 2007. p. 217-258.

10 Dentre os casos julgados pelo STF envolvendo liberdade de expressão, destaca-se o julgamento de não-recepção da Lei de Imprensa (ADPF 130), de liberdade de manifestação em ambientes públicos (STF, DJ 31 ago. 2007, ADI 1969/DF, Rel. Min. Ricardo Lewandowski), ainda que para defesa de posições que poderiam ser enquadradas como apologia ao crime, como a 'Marcha da Maconha' (BRASIL. Supremo Tribunal Federal. ADPF 187/DF, Rel. Min. Celso de Mello. DJ, 29 maio 2014), de possibilidade de criminalização do discurso do ódio (caso Ellwanger - STF, DJ 19 mar. 2003, 
Fora dessa proposição genérica, contudo, não parece haver consenso de quando a liberdade de expressão deverá ser garantida, nem em como implementar essa garantia na prática.

O presente trabalho propõe, assim, uma racionalização na atividade jurisdicional envolvendo a liberdade de expressão, com a construção e referência de um instrumental técnico por meio de premissas teóricas consistentes que tracem perspectivas e limites para a atividade jurisdicional envolvendo liberdade de expressão ${ }^{11}$. A esperança última é que a liberdade de expressão saia fortalecida nessa equação - isso não significa que ela sempre deva prevalecer, mas uma visão mais abrangente evitaria que o seu comprometimento em múltiplas ocasiões isoladas resultasse no seu enfraquecimento em larga escala.

O exemplo primordial desse modelo proposto é o norte-americano, em que a Suprema Corte desenvolveu um extenso e complexo aparato teórico para julgar casos envolvendo a Primeira Emenda (fundamento da liberdade de expressão na Constituição dos Estados Unidos). Esse modelo será explicado e desenvolvido na SEGUNDA parte do trabalho. A PRIMEIRA, por sua vez, cuidará de introduzir o debate sobre minimalismo e maximalismo nas decisões judiciais; estas últimas, por buscarem fundamentos decisórios que transcendem o caso concreto, tendem a produzir um modelo mais favorável à racionalização aqui discutida. Por fim, avaliando as críticas ao modelo norte-americano, a TerceIra parte pretende defender a aplicação desse modelo ao cenário jurídico brasileiro.

HC 82424/RS, Rel. p/ acórdão Min. Maurício Corrêa), possibilidade de humor e sátiras por veículos de radiodifusão durante o período eleitoral (BRASIL. Supremo Tribunal Federal. ADI 4451 MC-REF/DF, Rel. Min. Ayres Britto. DJ, $1^{\circ}$ jul. 2011) e desnecessidade de autorização do biografado para publicação de biografias (ADI 4815, Rel. Min. Carmen Lúcia).

11 A racionalização não significa que outras decisões, formadas fora desse contexto, sejam desprovidas de racionalidade. Naturalmente, a presunção é de que toda atividade judicante seja (ou deva ser) racional, fundamentada com base em premissas jurídicas razoáveis e tendo sempre como referência a lei ou a Constituição v. BARCELLOS, Ana Paula de. Ponderação, racionalidade e atividade jurisdicional. Rio de Janeiro: Renovar, 2005. p. 39. No entanto, em casos envolvendo conflitos entre direitos fundamentais ou princípios constitucionais dotados de alto teor axiológico, em que o texto normativo (legal e constitucional) oferecem pouca orientação para sua solução no caso concreto, a margem de liberdade conferida ao intérprete é muito maior.

\section{Notas sobre minimalismo e perfeccionismo nas decisões judiciais}

O tema em discussão está relacionado com o debate entre o minimalismo e o perfeccionismo/maximalismo nas decisões judiciais: afinal, ao decidir determinado caso, o julgador deve limitar-se a enfrentar as circunstâncias do caso concreto, ou deve assumir uma atitude mais ambiciosa, recorrendo a premissas e considerações constitucionais que transcendem o caso individual? $\mathrm{O}$ minimalismo defende a primeira concepção, sugerindo que o intérprete limite suas considerações decisórias apenas às questões imprescindíveis no caso individual a ele submetido, “deixando, na maior medida possível, questões normativas contíguas, profundas e controversas em aberto"12. O perfeccionismo, em contrapartida, propõe que as decisões judiciais sejam proferidas com fundamento em visões substantivas acerca das questões constitucionais em jogo, muitas vezes fixando premissas e orientações sobre como deverão ser julgados outros casos similares no futuro ${ }^{13}$.

Cass Sunstein ${ }^{14}$, um dos principais defensores do minimalismo enquanto técnica decisória ${ }^{15}$, afirma que as

12 SILVA, Alexandre Garrido da. Minimalismo, democracia e expertise: o Supremo Tribunal Federal diante de questões políticas e científicas complexas. Revista de Direito do Estado, Rio de Janeiro, n. 12, p. 115, out./dez. 2008.

13 SILVA, Alexandre Garrido da. Minimalismo, democracia e expertise: o Supremo Tribunal Federal diante de questões políticas e científicas complexas. Revista de Direito do Estado, Rio de Janeiro, n. 12, p. 111, out./dez. 2008: "O enfrentamento de tais questões profundamente controvertidas na sociedade é realizado com o objetivo de delinear standards de orientação para casos semelhantes no futuro, possuindo, assim, amplos efeitos prospectivos. Votos ou decisões de magistrados perfeccionistas procuram posicionar-se sobre como serão decididas outras questões no futuro (relacionadas ou não com o caso), exercendo, assim, forte orientação e apelo persuasivo sobre a atuação dos demais poderes. O seu discurso é, em regra, fortemente abstrato, permeado por considerações axiológicas, preocupado com o futuro e também amplo, no sentido de abordar outros temas ou questões que não seriam indispensáveis para a solução do caso sob exame".

14 SUNSTEIN, Cass. One case at a time: judicial minimalism on the Supreme Court. Cambridge: Harvard University Press, 2001.

15 O minimalismo e perfeccionismo aqui discutido é aquele referente a uma técnica decisória e interpretativa. Com efeito, os dois termos podem ser utilizados em diversos contextos, como para designar como perfeccionistas determinadas teorias constitucionais que imponham uma concepção específica sobre a Constituição, e minimalistas outras teorias que, face ao pluralismo e da divergência sobre diversas concepções de mundo, propõem uma visão 
decisões minimalistas são (i) "superficiais e não profundas" e (ii) "estreitas e não amplas"16. Enquanto superficiais, as decisões limitam-se a decidir aquele caso, sem tecer maiores considerações sobre todas as variáveis que estão em jogo. Enquanto estreitas, as decisões não querem pensar sobre como serão decididas questões futuras, nem fixar premissas que orientem os demais casos. O processo decisório, portanto, é feito de pequenos passos. A intenção do minimalismo é reduzir os custos (sobretudo de erros) decisórios: a atividade jurisdicional é mais fácil e melhor produzida se os intérpretes não precisarem fazer considerações teóricas e abstratas sobre todas as questões constitucionais em jogo, o que não apenas impossibilita ou dificulta o alcance de um consenso, bem como reduz o espaço de deliberação democrática ${ }^{17}$. Quanto a esse aspecto, o autor defende a justificação das decisões com fundamento em acordos incompletamente teorizados (incompletely theorized agreements): as decisões podem ser produzidas ainda que as pessoas divirjam quanto aos valores em jogo, bastando que elas concordem quanto ao seu resultado. Isto é, uma decisão pode ser proferida e os interesses compostos mesmo quando os diversos lados tenham concepções diferentes sobre os valores e direitos envolvidos.

A despeito disso, Sunstein reconhece, também, que o minimalismo apresenta deficiências e pode não ser aplicado em todos os casos. Nesse aspecto, o autor sustenta que o minimalismo acaba sendo também uma forma de perfeccionismo; da mesma forma que o próprio perfeccionismo, o originalismo ou o thayerismo - que

reduzida sobre os valores contidos na Constituição. Para uma diferenciação entre oito tipos de perfeccionismo, v. FLEMING, James E. The Incredible Shrinking Constitutional Theory: from the oartial Constitution to the minimal Constitution. Fordham Law Review, New York, v. 75, p. 2.887, maio 2007.

16 SUNSTEIN, Cass. Beyond judicial minimalism. Preliminary draft 9/25/08. Harvard University Public Law and Legal Theory, Working Paper No. 08-40, Cambridge, p. 2, 2007.

17 SUNSTEIN, Cass. Beyond judicial minimalism. Preliminary draft 9/25/08. Harvard University Public Law and Legal Theory, Working Paper No. 08-40, Cambridge, p. 4, 2007: "By avoiding depth and width, minimalists hope to reduce decision-making burdens. Emphasizing what judges do not know, minimalists characteristically believe that theoretical depth, and width, will produce a great deal of trouble for the future. Minimalists need not speak only in these terms. They might add that if certain foundational questions are unresolved, citizens and representatives have room to debate them, in a way that is valuable for democratic reasons". defende que somente violações expressas à Constituição poderiam ser invalidadas pelo Poder Judiciário -, o minimalismo é também uma teoria de como a Constituição deve ser entendida e interpretada ${ }^{18}$. Trata-se de o que o autor chama de perfeccionismo de segunda ordem: visões que também representam concepções perfeccionistas de decisões judiciais, mas que são preferíveis ao perfeccionismo de primeira ordem tradicional, uma vez que reconhecem as limitações do Poder Judiciário e que a escolha entre diversos modos de decidir (minimalismo, originalismo e thayerismo) dependerá de diversas variáveis ${ }^{19}$.

Nessa linha, o autor reconhece que, em determinadas condições e situações, haverá grande presunção contra o uso de fundamentos minimalistas. Em certas matérias, a predicabilidade das decisões judiciais e a segurança jurídica são elementos muito importantes, de modo que uma sequência de decisões judiciais minimalistas não poderia firmar premissas para guiar a atuação dos tribunais inferiores, incrementando a insegurança e uma jurisprudência caótica na área ${ }^{20}$. Sunstein exemplifica a função didática exercida pela Suprema Corte norte-americana quanto às questões sobre as garantias do processo penal (Miranda v. Arizona) ${ }^{21}$ e nos julgados da Suprema Corte sobre obscenidade, em que os testes firmados em Miller puseram fim a uma jurisprudência caótica sobre a matéria $(v \text {. infra })^{22}$. Em outras hipóteses, ademais, é impor-

18 SUNSTEIN, Cass. Second-order perfectionism. Public Law and Legal Theory Working Paper No. 144, Chicago, dez. 2006.

19 SUNSTEIN, Cass. Second-order perfectionism. Public Law and Legal Theory Working Paper No. 144, Chicago, p. 18., dez. 2006.

20 SUNSTEIN, Cass. Beyond judicial minimalism. Preliminary draft 9/25/08. Harvard University Public Law and Legal Theory, Working Paper No. 08-40, Cambridge, p. 14, 2007: "Suppose that a court is operating in a domain where predictability is extremely important - as, for example, because the issue comes up often, because people need guidance, and because it is simply too messy to have to proceed without a sense of what the law is. If this is so, narrow rulings will impose significant decisionmaking burdens on others-and very possibly increase decision costs on balance. Imagine, for example, that the question is the appropriate scope of review of judicial review of agency interpretations of law. That question arises with great frequency, and if a high court does not issue a wide ruling, then lower courts will have to handle a lot of uncertainty. If an area of law is a mess, because of a series of narrow rulings, posterity might be harmed rather than helped".

21 Miranda v. Arizona, 384 U.S. 436 (1966).

22 SUNSTEIN, Cass. Beyond judicial minimalism. Preliminary draft 9/25/08. Harvard University Public Law and Legal Theory, Working Paper No. 08-40, Cambridge, p. 15, 2007. 
tante que os tribunais consolidem orientações firmes e definitivas para promover valores democráticos - Brown v. Board of Education, que deu fim à segregação racial, é um exemplo clássico. Nesses casos, decisões profundas e ambiciosas foram importantes para o estabelecimento de uma jurisprudência protetiva dos direitos e garantias individuais e para o regime democrático ${ }^{23}$.

Um exemplo prático do debate entre minimalismo e perfeccionismo reside na distinção - tradicional no direito norte-americano - entre rules e standards ${ }^{24}$. Os defensores dos primeiros sustentam a prevalência de regras precisas no ordenamento jurídico; ao fixar um precedente e definir casos futuros, os tribunais devem estabelecer regras objetivas - determinada conduta é permitida, determinada conduta é proibida. Os defensores dos standards, por sua vez, acreditam na construção de conceitos mais fluidos, que deem maior liberdade ao intérprete, tais como a utilização de conceitos jurídicos indeterminados ou de testes específicos. Naturalmente, como destaca Sunstein, as razões que justificam o minimalismo são similares às que sustentam a prevalência de parâmetros em detrimento de regras ${ }^{25}$. Nada obstante, a utilização tão somente de razões minimalistas impedirá os tribunais até mesmo de formular parâmetros mais abertos ${ }^{26}$. Nesse aspecto, serão necessárias decisões perfeccionistas para que os tribunais definam, com base em determinados casos, os elementos e premissas que deverão ser levados em consideração na análise de casos similares. A escolha por regras precisas ou mais fluidas, por sua vez, dependerá da

23 SUNSTEIN, Cass. Beyond judicial minimalism. Preliminary draft 9/25/08. Harvard University Public Law and Legal Theory, Working Paper No. 08-40, Cambridge, p. 20, 2007: "It is true that more ambitious decisions create real losers, who will not be pleased to find that their defining commitments have been ruled off-limits. But sometimes the losers deserve to lose".

24 O tema é bastante rico na doutrina norte-americana. V., por todos, SULLIVAN, Kathleen M. The Supreme Court 1991 Term - Foreword: the justices of rules and standards. Harvard Law Review, Cambridge, v. 106, p. 22-123, jan. 1993; SCHLAG, Pierre J. Rules and standards. UCLA Law Review, Los Angeles, v. 33, p. 379-406, dez. 1985.

25 SUNSTEIN, Cass. Beyond judicial minimalism. Preliminary draft 9/25/08. Harvard University Public Law and Legal Theory, Working Paper No. 08-40, Cambridge, p. 15-16, 2007.

26 SILVA, Alexandre Garrido da. Minimalismo, democracia e expertise: o Supremo Tribunal Federal diante de questões políticas e científicas complexas. Revista de Direito do Estado, Rio de Janeiro, n. 12, p. 116, out./dez. 2008: "Em síntese, são adeptos do minimalismo os juízes que procuram evitar regras gerais e teorias abstratas, $[\ldots] "$. natureza dos direitos em jogo - em muitas hipóteses será inviável a definição das regras precisas sem o comprometimento total dos direitos em jogo - e do grau de liberdade que o intérprete quiser conferir para os casos futuros.

Em síntese: ao decidir, os magistrados podem valer-se de fundamentações minimalistas ou perfeccionistas. As primeiras limitam-se a decidir o caso concreto, deixando abertas as resoluções para casos futuros e evitando tecer considerações substantivas sobre os valores em jogo. Elas reduzem os custos de erros das decisões judiciais e permitem que pessoas que compartilham diversas visões sobre a Constituição possam alcançar o mesmo resultado ainda que não concordem com todas as suas premissas (acordos incompletamente teorizados). As decisões perfeccionistas, por sua vez, pretendem valer-se de fundamentos que transcendem o caso individual e que possam ser utilizados também para casos futuros, muitas vezes com base em considerações substantivas profundas dos direitos em questão. As decisões perfeccionistas incentivarão um cenário de fixação de parâmetros, premissas e orientações para hipóteses futuras, podendo ser justificadas em cenários que imponham uma maior previsibilidade e segurança jurídica, ou que justifiquem a consagração de determinadas concepções.

A racionalização proposta no presente estudo, como se viu, envolve justamente a criação de parâmetros e referências para os julgamentos dos casos envolvendo liberdade de expressão, evitando-se o puro decisionismo do intérprete ao lidar com um conflito entre direitos fundamentais. Isso não significa abandonar o minimalismo, que poderá ser justificado em determinadas ocasiões, mas a fixação de tais parâmetros envolve naturalmente um papel mais ativista do intérprete ao buscar decidir os casos recorrendo a visões mais abrangentes que a do caso individual. A avaliação dos benefícios dessa visão à liberdade de expressão será explorada adiante.

\section{Parâmetros da Suprema Corte dos Estados Unidos sobre liberdade de expressão}

Ao longo de sua evolução quase centenária ${ }^{27}$, a Suprema Corte dos Estados Unidos construiu um arsenal teórico muito extenso sobre a liberdade de expressão. Dependendo do ponto de vista, a jurisprudência da Corte

27 A doutrina norte-americana sobre a Primeira Emenda começou a ser formulada na segunda década do século XX. 
pode ser entendida como um grande e sólido monumento a favor da Primeira Emenda, ou um intricado e complexo labirinto que favorece apenas o caos e a confusão. Não é necessário desenvolver o assunto por hora. Basta o registro preliminar de que há razoável consenso que os Estados Unidos apresentam um grau de sofisticação teórica da liberdade de expressão muito maior que as outras cortes, utilizando um número grande de critérios e parâmetros para avaliar os diferentes casos envolvendo a liberdade de expressão ${ }^{28}$. É possível apontar diversos fatores para tal, que envolvem desde o aspecto temporal - os mecanismos do judicial review nos Estados Unidos consagram-se muito antes do que nos demais países - até os elementos próprios do sistema da common law, em que, por conta dos efeitos vinculantes das decisões dos tribunais superiores, estimula muito mais a criação de parâmetros e premissas pelos juízes. Feito o registro, passa-se à exposição dos parâmetros.

\subsection{Parâmetro geral: restrições de conteúdo}

Em 1984, o Sr. Johnson, membro de um movimento comunista nos Estados Unidos, ateou fogo à bandeira norte-americana na Convenção do Partido Republicano, um ato simbólico de protesto contra as políticas adotadas pelo presidente Ronald Reagan. Numa decisão de cinco contra quatro, a Suprema Corte entendeu que o Sr. Johnson não poderia ser condenado por tal ato, declarando inconstitucional uma lei texana que proibia a queima de bandeiras ${ }^{29}$. Alguns anos antes, o Sr. David O'Brien, em uma demonstração pública contra a Guerra do Vietnã, queimou o documento de registro que o identificava como um homem apto a servir ao exército. A Suprema Corte considerou que a lei que proibia a queima desse tipo de documento era válida, mantendo a condenação ao Sr. O’Brien ${ }^{30}$.

Os dois casos envolvem o mesmo tipo de discurso - o discurso simbólico - e, apesar da distância temporal, não envolveram uma mudança na orientação da Suprema Corte. Pelo contrário, ambos aplicaram rigorosamente o mesmo critério para avaliar a constitucionalidade das leis

28 BARENDT, Eric. Freedom of speech. 2. ed. Oxford: Oxford University Press, 2007. p. 55: "Free speech law in the United States is much more complex than it is in other countries. One reason for this complexity is that the Supreme Court has formulated a number of distinctive free speech doctrines and principles [...].

29 Texas v. Johnson, 491 U.S. 397 (1989)

$30 \quad$ United States v. O'Brien, 391 U.S. 367 (1968). em jogo: a restrição de conteúdo. Em Texas v. Johnson, a Corte considerou que a lei texana que proibia a queima de bandeiras norte-americanas envolvia uma limitação de conteúdo (content-based) à liberdade de expressão: a lei não se dirigia a proteger a integridade física da bandeira, mas a de reprimir manifestações políticas que se utilizassem desse tipo de expressão como forma de defender suas ideias. "Por mais ofensiva que seja a expressão", afirmou a Corte, o governo não poderia impor a sua própria visão ao proibir uma forma de manifestação política. Em United States v. O'Brien, por sua vez, a Suprema Corte entendeu que a lei que proibia a queima de documentos de identificação tinha finalidades não-relacionadas com a supressão de determinados tipos de discurso (tais como, por exemplo, o interesse estatal em manter a possibilidade de identificação das pessoas), sendo, portanto, neutra em sua restrição à liberdade de expressão.

A distinção entre restrições que afetam o conteúdo do discurso (content-based) e aquelas que são neutras em relação ao conteúdo (content neutral) é o principal fundamento da doutrina e jurisprudência norte-americana sobre liberdade de expressão. $\mathrm{O}$ caso inaugural dessa distinção foi julgado alguns anos depois de O'Brien: em Police Department of Chicago v. Mosley, a Suprema Corte declarou inválida uma lei que proibia manifestações a 150 pés de distância de escolas, excetuando-se manifestações pacíficas envolvendo direitos trabalhistas ${ }^{31}$. No caso, a Corte afirmou que "mais do que tudo, a Primeira Emenda significa que o governo não tem o poder de restringir a expressão por conta da sua mensagem, suas ideias, sua matéria, ou o seu conteúdo"32. O julgamento envolveu duas premissas: (i) o Estado não pode restringir a manifestação de expressão em espaços públicos com fundamento no tipo de discurso ${ }^{33}$, e (ii) o Estado não pode discriminar determinado tipo de discurso em favor de outros ${ }^{34}$.

Police Dept. of City of Chicago v. Mosley, 408 U.S. 92 (1972).

32 Tradução livre do voto do Justice Marshall, escrevendo para uma Corte unânime.

33 HEYMAN, Stephen J. Freedom of speech \& human dignity. New Haven: Yale University Press, 2008. p. 82.

34 KAGAN, Elena. Private speech, public purpose: the role of governmental motive in first amendment doctrine. The University of Chicago Law Review, Chicago, v. 63, p. 430, Primavera 1996: "Just as in equal protection law the government may not discriminate among persons on the basis of majoritarian biases, so too in First Amendment law the government may not so distinguish among messages. The key principle with respect to motive is that the government may not limit speech on grounds of mere disapproval, no 
A partir de Mosley, a análise da constitucionalidade de leis frente à liberdade de expressão com base na neutralidade do conteúdo da restrição consagrou-se e seguiu uma acidentada e incompleta evolução na jurisprudência da Suprema Corte ${ }^{35}$, ganhando contornos e sutilezas próprios que serão explorados nos próximos tópicos. A ideia central, porém, não envolve dificuldade: as restrições com base em conteúdo estão sujeitas a um teste de constitucionalidade mais rigoroso - o escrutínio estrito (strict scrutinity) -, havendo uma presunção quase absoluta quanto à sua invalidade; já as restrições neutras em conteúdo - tradicionalmente referidas como restrições de tempo, local e modo (time, place and manner) - estariam sujeitas a um teste mais deferente, posteriormente referido como escrutínio intermediário (intermediate scrutinity).

As características de cada teste somente vieram a ser explicitadas pela Suprema Corte em julgados posteriores. A aplicação do escrutínio estrito em casos envolvendo a regulação com base em conteúdo somente veio alguns anos depois, em Carey v. Brown (1980), envolvendo uma lei muito parecida com a apreciada em Mosley: a restrição de manifestações perto de residências, com exceção daquelas envolvendo disputas trabalhistas ${ }^{36}$. Embora tenha mantido o entendimento quanto à invalidade da lei, o tribunal afirmou expressamente a possibilidade de restrição na expressão com base em conteúdo caso existisse um interesse estatal relevante para a restrição (compelling interest) e desde que esta fosse dirigida diretamente para atingir tal interesse (narrowly tailored) ${ }^{37}$. Tal escrutínio - que deixa pouco espaço para atuação estatal - voltou a ser utilizado no ano seguinte em Widmar v. Vincent $(1981)^{38}$ para declarar inconstitucional o regramento de uma universidade que criava restrições a grupos de estudo com fundamentos religiosos.

A construção da Suprema Corte, portanto, afas-

matter whose or how widely shared".

35 Para uma análise detalhada da evolução da jurisprudência da Suprema Corte sobre o tema, v. MACDONALD, Barry. Speech and distrust: rethinking the content approach to protecting the freedom of expression. Notre Dame Law Review, Notre Dame, v. 81, p. 1.347-1430, Issue 4, 2006.

36 Carey v. Brown, 447 U.S. 455 (1980).

37 Carey v. Brown, 447 U.S. 455 (1980): "And though we might agree that certain state interests may be so compelling that where no adequate alternatives exist a content-based distinction - if narrowly drawn - would be a permissible way of furthering those objectives, cf. Schenck v. United States, 249 U.S. 47 (1919), this is not such a case". tou uma interpretação absoluta (em Mosley) de que toda restrição de conteúdo fosse per se inválida, admitindo a possibilidade de o governo formular restrições desse tipo desde que presentes (i) um interesse estatal relevante (ii) que a restrição seja dirigida diretamente para o fim almejado, preservado amplamente outras formas de expressão. Tal teste passou a ser identificado como escrutínio estrito ${ }^{39}$. O parâmetro cria um gigantesco ônus para o Estado justificar uma restrição à liberdade de expressão e, não por acaso, todos os casos posteriormente analisados pela Suprema Corte envolvendo restrições com base em conteúdo foram considerados inconstitucionais ${ }^{40}$. A regulação de conteúdo, portanto, cria um ônus quase absoluto de invalidade frente à Primeira Emenda ${ }^{41}$.

Sob essas premissas - restrições de conteúdo que não foram justificadas pelo Estado segundo os critérios do escrutínio estrito - a Corte voltou a declarar a inconstitucionalidade de leis que restringiam a queima da bandeira nacional ${ }^{42}$, a edição de livros que divulgavam atos $\operatorname{criminosos}^{43}$, queima de cruz como ato de ódio racial $^{44}$, a manifestação política de juízes candidatos a cargos no Judiciário ${ }^{45}$, demonstrações públicas em frente a embai-

39 O teste de escrutínio estrito, criando uma presunção de inconstitucionalidade da lei avaliada foi inicialmente desenvolvido pela Corte em casos em casos envolvendo o direito à igualdade - Skinner v. State of Oklahoma, ex. rel. Williamson, 316 U.S. 535 (1942) - e depois importado para a temática da liberdade de expressão.

40 MACDONALD, Barry. Speech and distrust: rethinking the content approach to protecting the freedom of expression. Notre Dame Law Review, Notre Dame, v. 81, p. 1.364-1.365, Issue 4, 2006: "The Court's choice of the strict scrutiny analysis over the absolute neutrality standard implied that content restrictions at least theoretically could be used by the government to address regulatory problems tied to certain types of expression, provided it demonstrated a sufficiently compelling or persuasive need and a strong sensitivity to free speech interests in addressing it. In practice, however, the Court appears to have retained Mosley's absolute neutrality approach dressed up as a stringent balancing analysis. In the twenty cases commencing with Carey where a majority of the Court has applied a strict scrutiny standard for reasons of content discrimination, it has found every one to be unconstitutional".

41 Há, contudo, diversas exceções em que mesmo a regulação de conteúdo foi permitida, tais como nos casos de discursos não protegidos ou quando a Corte justifica a manutenção da lei com base nos seus "efeitos secundários". O tema será retomado adiante.

$42 \quad$ United States v. Eichman, 496 U.S. 310 (1990).

43 Simon \& Schuster v. Crime Victims Board, 502 U.S. 105 (1991).

$44 \quad$ R.A.V. v. City of St. Paul, 505 U.S. 377 (1992).

45 Republican Party of Minnesota v. White, 536 U.S. 765 (2002). 
$\operatorname{xadas}^{46}$, dentre outros ${ }^{47}$. Em todos esses casos, a identificação de uma restrição com base no conteúdo do discurso foi um fator decisivo para a declaração de invalidade das leis.

Por outro lado, as restrições neutras em conteúdo (content-neutral) mostraram uma Corte profundamente deferente às restrições estatais; na quase totalidade de casos identificados dessa forma, a Suprema Corte reconheceu a validade das leis questionadas ${ }^{48}$. As restrições neutras são aquelas tradicionalmente identificadas como de tempo, local e modo (time, place and manner): o Estado não pode regular o conteúdo do discurso, mas pode delimitá-lo em circunstâncias específicas e bem identificadas. Assim, como visto, uma proibição de expressão de determinados tipos de discursos perto de escolas é identificada como baseada em conteúdo e, portanto, inconstitucional. Nada obstante, uma lei que restringisse a divulgação de qualquer discurso perto de escolas durante o horário da aula - como uma forma de não atrapalhar as atividades escolares - seria classificada como neutra em conteúdo e possivelmente seria validada pela Suprema Corte.

A maior tolerância a leis desse tipo é muito anterior à construção da moderna doutrina das restrições em base de conteúdo e data do período pós-Lochner, quando a Corte passou a adotar uma postura mais deferente ao Estado em matéria econômica ${ }^{49}$. A conciliação da nova postura deferente da Corte com a proteção de direitos individuais veio com a famosa nota de rodapé $n^{\circ} 4$ do caso Carolene Products ${ }^{50}$, que justifica uma postura mais ativista do Judiciário em casos envolvendo violações de preceitos específicos da Constituição, bem como em situações de bloqueio do processo político, notadamente em prejuízo de minorias insuladas da política majoritária. Naturalmente, como consta da própria nota de rodapé e é explorado no famoso trabalho de John Hart Ely

Boos v. Barry, 485 U.S. 312 (1988).

47 Para um levantamento, v. MACDONALD, Barry. Speech and distrust: rethinking the content approach to protecting the freedom of expression. Notre Dame Law Review, Notre Dame, v. 81, p. 1.375, Issue 4, 2006.

48 MACDONALD, Barry. Speech and distrust: rethinking the content approach to protecting the freedom of expression. Notre Dame Law Review, Notre Dame, v. 81, p. 1.370, Issue 4, 2006.

49 V. BHAGWAT, Ashutosh. The test that ate everything: intermediate scrutiny in First Amendment jurisprudence. University of Illinois Law Review, Chicago, v. 2007, p. 786, n. 3, 2007.

50 United States v. Carolene Products Company, 304 U.S. 144 (1938), sobre a concepção procedimental do judicial review ${ }^{51}$, os casos envolvendo a Primeira Emenda se encaixam perfeitamente na exceção apresentada pela Corte. A partir daí, começa a percepção da Corte de que alguns casos envolvendo a liberdade de expressão exigiriam uma postura mais ativista da Corte, ao passo que outros permitiriam maior liberdade ao legislador.

Assim, mesmo antes dos casos em que a Corte encampou o critério de restrição de conteúdo, o tribunal já havia mantido leis que previam limitações acidentais à liberdade de expressão. Em Kovacs v. Cooper (1949), a Corte declarou a constitucionalidade de lei que proibia o uso de carros de som em ruas públicas, sob a premissa de que o Estado tinha um interesse legítimo em garantir a tranquilidade e a segurança daqueles locais ${ }^{52}$. A Corte, também, validou diversas leis que previam a necessidade de obtenção de licenças ou permissões para determinadas atividades, tais como a distribuição de livros ou realização de manifestações ${ }^{53}$. A partir de Consolidated Edison Co. $v$. Public Service Comission (1980), decidido no mesmo dia que o caso Casey, a Corte traçou uma clara distinção entre as restrições de conteúdo e aquelas de "tempo, local e modo que sirvam a um relevante interesse e deixam abertos amplos canais alternativos de comunicação" ${ }^{54}$. Em Heffron v. International Society for Krishna Consciousness (1981), esses critérios passaram a ser utilizados para a avaliação de restrições de time, place and manner, numa atitude notadamente mais deferente pela Suprema Corte ${ }^{55}$.

Curiosamente, os critérios definidos pela Corte para o intermediate scrutinity foram desenvolvidos num caso que não envolvia uma restrição de time, place and manner - ou, pelo menos, não foi assim considerado pelos Justices. Trata-se do United States $v$. O’Brien, visto anteriormente, sobre discurso simbólico (no caso, queima de documentos de identificação). O Chief Justice Warren, escrevendo pela Corte, afirmou

51 Em português, v. ELY, John Hart. Democracia e desconfiança: uma teoria do controle judicial de constitucionalidade. São Paulo: M. Fontes, 2010.

$52 \quad$ Kovacs v. Cooper, 336 U.S. 77 (1949).

53 Saia v. New York, 334 U.S. 558 (1948) e Lovell v. City of Griffin, 303 U.S. 444 (1938).

54 Consolidated Edison Co. v. Public Service Commission, 447 U.S. 530 (1980).

55 Heffron v. International Society for Krishna Consciousness, 452 U.S. 640 (1981). Na ocasião, a Suprema Corte validou uma lei que estabelecia restrições à distribuição de materiais religiosos em feiras organizadas por órgãos ou instituições governamentais. 
a validade da lei restritiva, uma vez que ela (i) estava fundamentada em algum poder constitucional do Estado, (ii) dirigia-se a um importante ou substancial interesse do Estado, (iii) não estava relacionada com a supressão da liberdade de expressão, (iv) trata-se de restrição incidental à Primeira Emenda, proporcional ao interesse perseguido ${ }^{56}$.

O teste O'Brien (i.e., o teste de escrutínio intermediário) foi aperfeiçoado posteriormente pela Corte em Ward v. Rock Against Racism (1989) ${ }^{57}$. Ao validar uma lei de Nova Iorque que restringia os equipamentos sonoros que poderiam ser utilizados em demonstrações musicais no Central Park, a Corte criou um teste em três partes: (1) a restrição para ser válida deve ser justificada sem referência ao conteúdo da expressão regulada; (2) a restrição deve ser dirigida restritamente (narrowly tailored) para a assunção de um interesse estatal relevante e (3) a restrição deve deixar abertos amplos canais alternativos de comunicação.

Em Ward, ademais, o tribunal também afirmou que a aplicação do escrutínio intermediário não exige que o Estado sempre se utilize do meio menos restritivo à liberdade de expressão para atingir sua finalidade: basta que a restrição seja válida à luz dos parâmetros criados, independentemente de existirem outros meios disponíveis e menos onerosos ${ }^{58}$. Nesse aspecto, o teste do escrutínio intermediário é muito menos rigoroso que o teste de proporcionalidade do direito germânico e que consagrou-se no direito brasileiro - neste, como se sabe, a restrição aos direitos fundamentais deve ser a menor possível, devendo o legislador escolher sempre a medida

$56 \quad$ United States v. O'Brien, 391 U.S. 367 (1968): "Whatever imprecision inheres in these terms, we think it clear that a government regulation is sufficiently justified if it is within the constitutional power of the Government; if it furthers an important or substantial governmental interest; if the governmental interest is unrelated to the suppression of free expression; and if the incidental restriction on alleged First Amendment freedoms is no greater than is essential to the furtherance of that interest".

57 Ward v. Rock Against Racism, 491 U.S. 781 (1989).

58 Ward v. Rock Against Racism, 491 U.S. 781 (1989): "The requirement of narrow tailoring is satisfied so long as the regulation promotes a substantial governmental interest that would be achieved less effectively absent the regulation, and the means chosen are not substantially broader than necessary to achieve that interest. If these standards are met, courts should defer to the government's reasonable determination". V. FARBER, Daniel A. The First Amendment. 3. ed. New York: Thomsom Reuters/Foundation Press, 2010. p. 25. menos restritiva para alcançar o fim almejado (teste de necessidade $)^{59}$.

O teste de O'Brien/Ward consagrou-se na jurisprudência da Primeira Emenda e tem sido utilizado sempre que os tribunais enfrentam restrições à liberdade de expressão que julgam ser neutras em conteúdo. Com base nessas premissas, a Suprema Corte reconheceu a validade de leis que restringiam determinados tipos de manifestações perto de clínicas de aborto ${ }^{60}$, restringiam a localização de estabelecimentos "adultos" e com apresentações de danças eróticas ${ }^{61}$, restringiam a realização de protestos perto de residências ${ }^{62}$, restringiam a realização de solicitações públicas e distribuições de materiais em calçadas dos prédios de agências dos correios ${ }^{63}$, exigiam que canais de televisão a cabo exibissem determinados conteúdos educacionais em sua programação ${ }^{64}$, proibiam a divulgação, por terceiros, de uma conversa telefônica privativa ${ }^{65}$, dentre outros.

A despeito da tradicional identificação do escrutínio intermediário com as restrições neutras em conteúdo e de "tempo, local e modo", há autores que sustentam a existência de um único teste de escrutínio estrito - o mesmo definido em O’Brien e Ward - para diversas situações e discursos diferentes. Ashutosh Bhagwat ${ }^{66}$, por exemplo, afirma que os mesmos parâmetros foram utilizados pela Suprema Corte em casos envolvendo (i) restrições sobre discurso simbólico (sendo o próprio O’Brien um exemplo disso); (ii) regulação sobre a mídia ${ }^{67}$; (iii) restrições sobre o discurso comercial ${ }^{68}$; (iv) restrições sobre a ex-

59 Sobre o tema, v. PEREIRA, Jane Reis Gonçalves. Interpretação constitucional e direitos fundamentais: uma contribuição ao estudo das restrições aos direitos fundamentais na perspectiva da teoria dos princípios. Rio de Janeiro: Renovar, 2006. p. 337 e ss.

60 Hill v. Colorado, 530 U.S. 703 (2000).

${ }_{61} \quad$ Erie v. Pap's A. M., 529 U.S. 277 (2000).

$62 \quad$ Frisby v. Schultz, 487 U.S. 474 (1988).

63 United States v. Kokinda, 497 U.S. 720 (1990).

64 Turner Broadcasting System, Inc.. v. F.C.C. (93-44), 512 U.S. 622 (1994).

65 Bartnicki v. Vopper, 532 U.S. 514 (2001).

66 BHAGWAT, Ashutosh. The test that ate everything: intermediate scrutiny in First Amendment jurisprudence. University of Illinois Law Review, Chicago, v. 2007, p. 787 e ss., n. 3, 2007.

67 O exemplo clássico é o Turner Broadcasting System, Inc.. v. F.C.C. já referido acima, em que a Corte analisou a validade de imposições sobre canais de televisão a cabo quanto ao conteúdo de sua programação, afirmando tratar-se de uma restrição de time, place and manner.

68 O ponto será explorado adiante. 
pressão de funcionários públicos ${ }^{69}$; (v) restrições sobre estabelecimentos "adultos" e de conteúdo sexual; (vi) restrições sobre solicitações de caridade; e (vii) restrições sobre doações eleitorais. Em todos esses casos - e muito embora possam envolver restrições sobre o conteúdo da expressão -, a Corte desenvolveu uma avaliação mais deferente aos interesses do Estado. Segundo o autor, isso significou a criação de um único grande teste de intermediate scrutinity para diversos tipos de restrições. O ponto pode ser confirmado com base na análise de centenas de casos de liberdade de expressões nos tribunais norte-americanos ${ }^{70}$. O resultado, na prática, tem sido decisões profundamente deferentes às restrições estatais ${ }^{71}$.

As críticas aos critérios da Suprema Corte serão enfrentadas adiante. Por hora basta o registro de que a construção da Suprema Corte em distinguir restrições de conteúdo daquelas neutras em conteúdo ganhou grande adesão da doutrina, pelo menos no período imediatamente posterior à sua concepção. Em um influente trabalho sobre discurso simbólico publicado pouco tempo após O'Brien e Mosley, Melville B. Nimmer encampou os critérios utilizados pela Suprema Corte - ainda em fase embrionária - de diferenciar atos comunicativos com significados e atos comunicativos sem significado ${ }^{72}$; ao passo que os primeiros não admitiriam restrição estatal, os segundos poderiam ser restringidos ${ }^{73}$. Posteriormente, o autor desenvolveu uma distinção, bem mais próxima da utilizada pela Suprema Corte, entre restrições dirigidas ao conteúdo da comunicação e restrições dirigidas à conduta da comunicação $0^{74}$. As primeiras seriam consideradas pre-

69 Nesses casos, as restrições envolvem justamente o conteúdo da mensagem difundida por funcionários públicos, muito embora a Corte aplique um teste similar ao escrutínio intermediário de time, place and manner. V. Pickering v. Board of Education, 391 U.S. 563 (1968).

70 BHAGWAT, Ashutosh. The test that ate everything: intermediate scrutiny in First Amendment jurisprudence. University of Illinois Law Review, Chicago, v. 2007, p. 802 n. 3, 2007.

71 BHAGWAT, Ashutosh. The test that ate everything: intermediate scrutiny in First Amendment jurisprudence. University of Illinois Law Review, Chicago, v. 2007, p. 821, n. 3, 2007.

72 NIMMER, Melville B. The meaning of symbolic speech under the First Amendment. UCLA Law Review, v. 21, p. 29- 1973.

73 Encampanhando essa mesma distinção, v. ELY, John Hart. Flag desecration: a case study in the roles of categorization and balancing in First Amendment analysis. Harvard Law Review, v. 88, p. 1.497, 1975.

74 NIMMER, 1984 apud SHIFRRIN, Steven H. The First Amendment, democracy and romance. Princeton: Princeton University Press, 1990. p. 11. sumivelmente inconstitucionais, ao passo que as segundas gozariam de presunção de constitucionalidade, aplicando-se o teste de O’Brien. A ideia seria organizar uma teoria que não dependesse de ponderação pura e simples, mas de regras ou, quando muito, definitional balancing - isto é, a ponderação por meio de critérios previamente definidos ${ }^{75}$.

Em dois importantes trabalhos sobre os critérios formulados pela Suprema Corte, Geoffrey Stone estudou a compatibilidade da distinção de restrições sobre o conteúdo com a teoria da liberdade de expressão ${ }^{76}$. Em primeiro lugar, para o autor, a distinção atende à tradicional proteção à liberdade de expressão por conta do livre mercado de ideias: caso o governo tivesse liberdade para impor limitações ao conteúdo dos discursos existentes na sociedade, os cidadãos teriam acesso apenas a informações parciais, incompletas e distorcidas, impedindo que possam alcançar a verdade através da livre avaliação das ideias que competem no mercado ${ }^{77}$. As restrições neutras em conteúdo, porém, também podem limitar o acesso do público a ideias e informações relevantes ${ }^{78}$; por isso justifica-se a resposta da Suprema Corte ao criar um teste intermediário que permite sopesar os interesses do Estado com as restrições à liberdade de expressão ${ }^{79}$.

75 NIMMER, 1984 apud SHIFRRIN, Steven H. The First Amendment, democracy and romance. Princeton: Princeton University Press, 1990. p. 2-15.

${ }_{76}$ STONE, Geoffrey R. Content regulation and the First Amendment. Willian and Mary Law Review, Williamsburg, v. 25, n. 2, p. 189-252, Inverno 1983. p. 189-252; STONE, Geoffrey R. Restriction of speech because of its content: the peculiar case of subject-matter restrictions. The University of Chicago Law Review, Chicago, v. 46, p. 81-115, Issue 1, 1978.

77 STONE, Geoffrey R. Restriction of speech because of its content: the peculiar case of subject-matter restrictions. The University of Chicago Law Review, Chicago, v. 46, p. 101, Issue 1, 1978. A metáfora do mercado de ideias é uma das prevalecentes na justificativa à proteção à liberdade de expressão, estando geralmente relacionada com a busca pela verdade. Sobre o tema, com ampla indicação bibliográfica, v. EMERSON, Thomas. Toward a general theory of the First Amendment. The Yale Law Journal, Yale, v. 72, p. 877-956, Abril 1963.

78 STONE, Geoffrey R. Restriction of speech because of its content: the peculiar case of subject-matter restrictions. The University of Chicago Law Review, Chicago, v. 46, p. 101-102, Issue 1, 1978.

79 STONE, Geoffrey R. Content regulation and the First Amendment. Willian and Mary Law Review, Williamsburg, v. 25, n. 2, p. 192-193, Inverno 1983: "The Court's primary concern in the content-neutral realm is that such restrictions, by limiting the availability of particular means of communication, can significantly impair the ability of individuals to communicate their views to others. This is, 
Em segundo lugar, Stone afirma que a distinção da Suprema Corte sobre as restrições em conteúdo também justifica-se como consequência da tradicional visão da imparcialidade do governo em matéria de liberdade de expressão: o Estado não pode restringir determinados discursos apenas porque os desaprova ou teme ${ }^{80}$. Essa visão é compatível tanto com as perspectivas da proteção da liberdade de expressão como busca pela verdade, como de autogoverno democrático e de realização da autonomia individual - são as pessoas que devem avaliar quais a informações e ideias merecem proteção ou não, e não o governo ${ }^{81}$. Essa premissa justificaria, por exemplo, a ampla proteção garantida pela Suprema Corte ao hate speech (v. infra).

\subsection{O ponto complicador: restrições de matéria (subject matter) e restrições de ponto de vista (viewpoint discrimination)}

Acaso fosse claro identificar as restrições que invadem o conteúdo da expressão e aquelas que sejam neutras nesse sentido, seria fácil avaliar a constitucionalidade de limites à liberdade de expressão pelos critérios construídos pela Suprema Corte. As leis e atos restritivos, contudo, não vêm com uma nota de rodapé "restrição de conteúdo: tomar cuidado”. Ao contrário, uma vez firmada a orientação da Corte, é natural que os órgãos estatais busquem disfarçar eventuais restrições de conteúdo por meio de regulações pretensamente neutras. Identificando essa dificuldade, a Corte passou a estabelecer dois subcritérios para diferenciar as restrições de conteúdo: restrições de matéria (subject matter) e restrições de ponto de

of course, a central first amendment concern,' for to the extent that contentneutral restrictions actually reduce the total quantity of expression, they necessarily undermine the "search for truth," impede meaningful participation in "self-governance," and frustrate individual "self-fulfillment." The Court's content-neutral balancing is a sensible response to this concern. Unlike a consistently deferential approach, which would uphold every content-neutral restriction that rationally furthers legitimate governmental interests, the Court's approach critically examines restrictions that seriously threaten significant first amendment interests".

80 STONE, Geoffrey R. Restriction of speech because of its content: the peculiar case of subject-matter restrictions. The University of Chicago Law Review, Chicago, v. 46, p. 102-110, Issue 1, 1978.

81 STONE, Geoffrey R. Restriction of speech because of its content: the peculiar case of subject-matter restrictions. The University of Chicago Law Review, Chicago, v. 46, p. 103-104, Issue 1, 1978. vista (viewpoint discrimination).

De forma sintética, as primeiras (subject matter) são aquelas que distinguem determinadas matérias, restringindo-as em detrimento de outras. Embora a princípio deveriam ser tratadas como restrições de conteúdo, a Suprema Corte entende que, como a restrição atinge todo um campo, e não apenas determinados conteúdos ou pontos de vista, elas devem ser avaliadas como restrições neutras em conteúdo (e, portanto, através dos parâmetros de O’Brien). Já as segundas (viewpoint discrimination) envolvem justamente o critério inverso: o Estado bane determinados pontos de vista do mercado de ideias, discriminando-os dos demais, de modo que se trata de restrições de conteúdo, aplicando-se o escrutínio estrito. A lógica é que as restrições de matéria, embora possam afetar o conteúdo dos discursos, representam menos perigo para a livre circulação de ideias, indicando também uma menor tendência do Estado de pretender banir certos pontos de vista. Por essa razão, as restrições de matéria podem sujeitar-se a um teste mais brando de avaliação ${ }^{82}$.

Alguns casos julgados pela Suprema Corte ajudam a ilustrar a distinção. Em CBS v. Democratic National Committee $(1973)^{83}$, a Corte afirmou a possibilidade de operadoras de rádio e televisão de se opor a vender tempo de publicidade a grupos ou indivíduos com posições políticas ou ideológicas contrárias às suas. Em seu voto pela Corte, o Chief Justice Warren Burger afirmou que o caso não envolvia discriminações a determinados tipos de discurso - não se trataria, portanto, de uma discriminação de ponto de vista. Em Lehman v. City of Shaker Heights (1974) $)^{84}$, a Corte declarou a constitucionalidade

82 STONE, Geoffrey R. Restriction of speech because of its content: the peculiar case of subject-matter restrictions. The University of Chicago Law Review, Chicago, v. 46, p. 108, Issue 1, 1978: "Subject-matter restrictions also distort the "marketplace of ideas" in a content-differential manner. But because they are at least facially viewpoint-neutral, the potential harm in this regard is somewhat more remote. Although not without difficulties, viewpointneutral restrictions directed against all speech relating to an entire subject do not have the same sort of skewing effect on "the thinking process of the community" as restrictions directed specifically against speech taking a particular side in an ongoing debate. Moreover, because of their apparent viewpoint-neutrality, subject-matter restrictions seem much less likely than other forms of content-based restrictions to be the product of governmental hostility to the ideas or information suppressed".

83 CBS v. Democratic National Committee, 412 U.S. 94 (1973).

84 Lehman v. City of Shaker Heights, 418 U.S. 298 (1974). 
de lei que permitia a divulgação de mensagens comerciais em ônibus, mas não de propagandas políticas. A lógica era de que toda a matéria política tinha sido banida, não havendo distinção entre diferentes pontos de vista - o que ocorreria, por exemplo, caso a lei restringisse apenas manifestações de candidatos republicanos, ou contrários ao aborto.

Em Erznoznik v. City of Jacksonville $(1975)^{85}$, a Corte invalidou uma lei que impedia cinemas drive-in de exibirem filmes com cenas eróticas, editada sob a premissa de que tais cenas poderiam ser vistas da rua ou de lugares públicos. A Corte considerou que a lei discriminava filmes de acordo com o seu conteúdo, sendo uma restrição de ponto de vista. Um caso decidido no ano seguinte parece, contudo, ir em sentido contrário. Em Young v. American Mini Theathres (1976) ${ }^{86}$, o tribunal considerou que uma lei que estabelecia limitações de localização a cinemas que exibissem material pornográfico era uma restrição de matéria, afastando a alegação de violação a Primeira Emenda. Além do argumento de ser um discurso de menor valor (low value speech - v. infra), o Justice Stevens, escrevendo pela Corte, afirmou que o ato normativo em questão "não viola a obrigação primordial do governo de neutralidade", uma vez que a restrição não "afeta a mensagem social, política ou filosófica que um filme queira passar, ou se ridiculariza um determinado ponto de vista" ${ }^{\prime 7}$.

Uma atitude similar foi adotada pela Suprema Corte em casos envolvendo discurso político e partidário. Além do Buckley v. Valeo - em que a Corte afirmou que as restrições de financiamento de campanha questionadas não representavam restrições de ponto de vista ${ }^{88}$-, em United States Civil Service Commission v. National Association of Letter Carriers (1973) ${ }^{89}$, a Corte afirmou que as restrições de manifestações partidárias por funcionários públicos eram válidas, uma vez que não se dirigiam a determinados grupos, partidos ou pontos de vista Nessa mesma linha, em Greer v. Spock (1976), a Corte afirmou que a proibição de manifestação política e distribuição de literatura política em área militar não viola a Primeira Emenda, tendo em vista ser neutra em conteúdo e não

85 Erznoznik v. City of Jacksonville, 422 U.S. 205 (1975).

86 Young v. American Mini Theatres, 427 U.S. 50 (1976).

87 Young v. American Mini Theatres, 427 U.S. 50 (1976).

88 Buckley v. Valeo, 424 U.S. 1 (1976).

89 United States Civil Service Commission v. National Association of Letter Carriers, 413 U.S. 548 (1973) fazer distinção de visão política ou partidária ${ }^{90}$.

A partir desses casos, a distinção entre subject-matter e viewpoint discrimination incorporou-se, sem maiores evoluções, na análise que a jurisprudência norte-americana realiza entre restrições sobre conteúdo e restrições neutras em conteúdo. Alguns casos subsequentes da Suprema Corte demonstram as dificuldades envolvidas nessa definição. Em Rosenberger v. Rector and Visitors of the University of Virginia (1995) ${ }^{91}$, a Corte - por cinco a quatro - julgou inconstitucional a atitude de uma universidade de atribuição de bolsas de estudos para determinadas matérias, excluindo expressamente pesquisas envolvendo questões religiosas. A apertada maioria afirmou que a exclusão da religião seria uma discriminação de ponto de vista, permitindo que as pesquisas de assuntos seculares tivessem um tratamento privilegiado na política da universidade.

Em Legal Services Corp. v. Velazquez (2001), a Suprema Corte declarou a inconstitucionalidade de uma lei que restringia que uma corporação governamental sem fins lucrativos (Legal Services Corporations), criada para proteger pessoas sem assistência jurídica, patrocinasse causas judiciais destinadas à reforma ou invalidação da welfare law ${ }^{92}$. A Corte afirmou que se tratava de uma discriminação sobre o conteúdo do discurso da corporação. Mais recentemente, em Sorrell v. IMS Health Inc. $(2011)^{93}$, a Corte derrubou uma lei que proibia a divulgação de dados médicos para as indústrias farmacêuticas - uma prática comum no mercado farmacêutico. Segundo a maioria, liderada pelo Justice Anthony Kennedy, o mercado farmacêutico não poderia ser considerado uma ampla "matéria" sujeita a restrições, de modo que a restrição dirigida exclusivamente às empresas farmacêuticas discriminava um determinado ponto de vista.

A consideração das restrições de matéria e de ponto de vista, portanto, adicionam ainda mais sutilezas e complexidade na jurisprudência da Suprema Corte sobre liberdade de expressão e a restrição de conteúdo. Não por outra razão, ainda no nascedouro da construção, GEOFFREY STONE já afirmava que "claridade e simplicidade são valores importantes na jurisprudência sobre a Primeira Emenda", de modo que talvez fosse mais fácil tratar todas

\footnotetext{
$90 \quad$ Greer v. Spock, 424 U.S. 828 (1976).

91 Rosenberger v. Rector and Visitors of the University of Virginia, 515 U.S. 819 (1995).

92 Legal Services Corp. v. Velazquez, 531 U.S. 533 (2001).

93 Sorrell v. IMS Health Inc., 131 S.Ct. 2653 (2011).
} 
as restrições sobre o mesmo critério (do escrutínio estrito $)^{94}$. O critério sobreviveu, de toda forma. Ao lado dele, a Suprema Corte também aplica, em hipóteses específicas, outros parâmetros para avaliar casos de liberdade de expressão. $\mathrm{O}$ tópico seguinte trata de alguns desses parâmetros e o subsequente de critérios específicos construídos para discursos que recebem menor proteção da Primeira Emenda.

\subsection{Parâmetros paralelos: overbreadth, vagueness, prior restraints, efeitos secundários e motivação governamental}

Os critérios secundários ou paralelos construídos pela Suprema Corte dos EUA não substituem os critérios das restrições de conteúdo e neutras em conteúdo, que continuam sendo a principal orientação da Corte em matéria de liberdade de expressão. Em algumas hipóteses, contudo, a Suprema Corte considerou outros fatores para avaliar casos envolvendo a Primeira Emenda e, eventualmente, invalidar leis restritivas à liberdade de expressão. Não há uma lista taxativa ou específica de quais critérios são esses. A seguir, passa-se à exposição de cinco principais parâmetros que já foram utilizados pela Corte.

I) Overbreadth - Por esse critério, uma lei restritiva da liberdade de expressão pode ser invalidada de plano (on its face - i.e., sem sequer ser necessário considerar o interesse estatal na restrição) ${ }^{95}$ caso ela seja superinclusiva em sua definição; a pretexto de restringir determinado tipo de expressão (geralmente, um discurso não protegido pela liberdade de expressão), o Estado acaba restringindo outros tipos de discursos. A lei, portanto, é desproporcional: restringe mais do que o necessário. Um exemplo clássico ${ }^{96}$ é o caso Board of Airport Commissioners of Los

94 STONE, Geoffrey R. Restriction of speech because of its content: the peculiar case of subject-matter restrictions. The University of Chicago Law Review, Chicago, v. 46, p. 114, Issue 1, 1978: "The difficulties in this analysis may suggest that the most prudent course is simply to test all subject-matter restrictions by the ordinarily stringent standards of content-based analysis. Clarity and simplicity are important values in first amendment jurisprudence, and acceptance of even a narrow' sacrifice of those values in this context might have unwelcome, long-range consequences".

95 A Suprema Corte admite, de forma excepcional, que uma lei inconstitucional seja questionada on its face antes mesmo da ocorrência de uma efetiva violação. Sobre o tema, v. FALLON JUNIOR., Richard H. Fact and fiction about facial challenges. California Law Review, Berkeley, v. 99, n. 4, p. 915-974, Agosto 2011.

96 A referência é de FARBER, Daniel A. The First Amendment. 3. ed. New York: Thomsom Reuters/Foundation Press, 2010. p. 48.
Angeles v. Jews for Jesus (1987) ${ }^{97}$, em que a Suprema Corte invocou a overbreadth doctrine para invalidar uma lei que restringia "todas as atividades de Primeira Emenda" em terminais de aeroporto. Reafirmando a jurisprudência de que a overbreadth doctrine é um remédio extremo ${ }^{98}$, a Corte considerou que é necessária a efetiva demonstração de que uma lei, por si só, ponha em perigo a Primeira Emenda.

II) Vagueness - A Suprema Corte também admite que uma lei que restrinja a liberdade de expressão seja invalidada on its face quando ela o faz de modo excessivamente vago ou impreciso, de modo que não é possível aferir a extensão e o conteúdo da restrição. Tradicionalmente, trata-se de casos em que o legislador delega ao administrador, sem formular critérios, a possibilidade de restrição de expressão. É o caso do julgado em $L a$ kewood v. Plain Dealer Publishing Co. (1988), em que a Corte invalidou uma lei que condicionava a colocação de anúncios em vias públicas a uma licença a ser concedida pela prefeitura, que poderia negá-la se fosse "necessário e razoável". A Corte afirmou que os limites da discricionariedade administrativa deveriam estar presentes no texto legal, orientando- $\mathrm{a}^{99}$.

III) Censura prévia (prior restraints) - Os riscos e a impossibilidade de censura prévia é um dos pilares da liberdade de expressão no direito comparado, constituindo o núcleo duro da liberdade de imprensa no direito inglês e norte-americano ${ }^{100}$. A repulsa da Suprema Corte dos Estados Unidos à censura prévia a publicações e outros tipos de expressão é antiga e tradicional em sua jurisprudência ${ }^{101}$. Em Near v. Minnesota (1931), a Corte derrubou uma decisão judicial que proibia um jornal de circular publicações

Board of Airport Commissioners of Los Angeles v. Jews for Jesus, Inc., 482 U.S. 569 (1987).

98 O primeiro precedente nesse sentido foi Broadrick $v$. Oklahoma, 413 U.S. 601 (1973).

99 Lakewood v. Plain Dealer Publishing Co., 486 U.S. 750 (1988).

100 BARENDT, Eric. Freedom of speech. 2. ed. Oxford: Oxford University Press, 2007. p. 117: "It is a commonplace observation that the law regards, and is right to regard, prior restraints on speech and writing with particular hostility. [...] Indeed, Blackstone considered freedom of the press 'consists in laying no previous restraints upon publication, and not in freedom from censure for criminal matter when published'. While the second part of that definition has often been criticized, the first has been treated as gospel, particularly in the United States where prior restraints are rarely counteranced. There is a heavy presumption against their constitutional validity [...]".

101 Patterson v. Colorado, 205 U.S. 454 (1907). 
maliciosas, escandalosas ou difamatórias, afirmando ser esta a "essência da censura"102. No famoso Pentagon Papers Case (1971) $)^{103}$, a Corte permitiu que jornais de grande circulação publicassem arquivos secretos do Pentágono, derrubando uma injunção que havia proibido tais publicações. Em Bantham Books, Inc. v. Sullivan (1963), a Corte considerou que já configurava uma censura prévia a mera divulgação, pelo governo, de uma "lista negra" de livros de conteúdo adulto, com ameaças de processo por obscenida$\mathrm{de}^{104}$. Não se trata, porém, de garantia absoluta: a Corte já aceitou injunções contra a publicação de livros que violavam sigilo contratual ${ }^{105}$.

IV) Efeitos secundários - Em algumas hipóteses, ao avaliar restrições neutras em conteúdo (ou seja, aplicando o teste O'Brien), um dos fatores considerados pela Corte para manter uma lei é a consideração de seus efeitos secundários, i.e., outros efeitos benéficos que uma lei que restringe a liberdade de expressão pode causar. A consideração dos efeitos secundários envolve, principalmente, casos de restrição de estabelecimentos e conteúdo obsceno. Em dois casos envolvendo restrições a danças eróticas (nude dancing), a Corte afirmou que se tratava de uma de restrição de matéria (subject-matter), validando as leis por conta de seus efeitos secundários na limitação da prostituição e da criminalidade próxima a estabelecimentos ${ }^{106}$. Em Renton v. Playtime Theathers, Inc. (1986), a Suprema Corte, enfrentando uma lei similar à analisada em Young (v. supra) validou a possibilidade de restrições à localização de cinemas com conteúdo adulto, afirmando expressamente que seria justificada a sua manutenção pelos efeitos secundários buscados pelo Estado, também relacionado com a diminuição da violência e prostituição perto de áreas residenciais ${ }^{107}$.

V) Motivação estatal - Como se viu, o teste de O’Brien para a avaliação de restrições neutras em conteú-

102 Near v. Minnesota, 283 U.S. 697 (1931): "This is of the essence of censorship. The question is whether a statute authorizing such proceedings in restraint of publication is consistent with the conception of the liberty of the press as historically conceived and guaranteed. In determining the extent of the constitutional protection, it has been generally, if not universally, considered that it is the chief purpose of the guaranty to prevent previous restraints upon publication".

103 New York Times Co. v. United States, 403 U.S. 713 (1971).

104 Bantham Books, Inc. v. Sullivan, 372 U.S. 58 (1963).

105 Snepp v. United States, 444 U.S. 507 (1980).

106 Barnes v. Glen Theatre, Inc., 501 U.S. 560 (1991) e Erie v. Pap's A. M., 529 U.S. 277 (2000).

107 Renton v. Playtime Theatres, Inc., 475 U.S. 41 (1986). do explicitamente rejeita a possibilidade de se avaliar a motivação estatal por trás de uma lei restritiva da liberdade de expressão. O Judiciário não deve verificar, portanto, alguma motivação indevida (improper motivation) no legislador ao editar uma lei (tal como, por exemplo, pretender restringir determinados tipos de discurso). $\mathrm{O}$ fundamento, desde O'Brien, é a dificuldade de se identificar a vontade do legislador em cada caso. Nada obstante, em estudo sobre o tema, Elena Kagan ${ }^{108}$ sustenta justamente que a inquirição da motivação estatal constitui, mesmo que de forma implícita, um dos pilares da jurisprudência da Suprema Corte sobre liberdade de expressão ${ }^{109}$.

\subsection{Parâmetros construídos para hipóteses específi- cas (categorização): discursos de menor valor}

A avaliação entre restrições de conteúdo e restrições neutras em conteúdo partem da premissa de que o discurso em questão recebe total proteção da liberdade de expressão sob a Primeira Emenda da Constituição dos Estados Unidos. Ocorre, porém, que a Suprema Corte não trata todos os tipos de discursos da mesma forma; em alguns casos, o discurso não receberá proteção alguma da liberdade de expressão (podendo, portanto, estar sujeito à ampla regulação estatal, inclusive de conteúdo) ou receberá um tratamento diferenciado, tendo em vista ser um discurso de menor valor para a Primeira Emenda. Nesses casos, a jurisprudência da Corte construiu uma verdadeira categorização da liberdade de expressão ${ }^{110}$, criando, ao longo da sua história, testes específicos para

108 KAGAN, Elena. Private speech, public purpose: the role of governmental motive in first amendment doctrine. The University of Chicago Law Review, Chicago, v. 63, p. 413517, Primavera 1996.

109 KAGAN, Elena. Private speech, public purpose: the role of governmental motive in first amendment doctrine. The University of Chicago Law Review, Chicago, v. 63, p. 414415, Primavera 1996: "I argue, notwithstanding the Court's protestations in O'Brien, that First Amendment law, as developed by the Supreme Court over the past several decades, has as its primary, though unstated, object the discovery of improper governmental motives. [...] I contend not that the Court self-consciously constructed First Amendment doctrine to ferret out improper motive, but that for whatever uncertain, complex, and unknow-able reasons, the doctrine reads as if it had been so constructed".

110 FARBER, Daniel A. The categorical approach to protecting speech in American Constitutional Law. Indiana Law Journal, Bloomington, v. 84, p. 917-938, Verão 2009; SCHAUER, Frederick. Categories and the First Amendment: a play in three acts. Vanderbilt Law Review, Nashville, v. 34, p. 265-308, Abril 1981. 
determinados tipos de discursos. A categorização é contrastada com o uso da ponderação pura e simples, permitindo que o intérprete identifique distinções de temas e formule padrões específicos para sua avaliação ${ }^{111}$. O escrutínio estrito e intermediário dos discursos plenamente protegidos, por sua vez, aproxima-se muito mais de um processo ponderativo puro e simples, embora com determinados parâmetros ${ }^{112}$.

Historicamente, a jurisprudência da Suprema Corte dividiu-se entre os discursos protegidos pela Primeira Emenda - em geral, expressão de conteúdo político - e o discursos que não gozavam dessa proteção (unprotected speech $)^{113}$. Na atual jurisprudência da Corte, construída nas últimas décadas, existem, ainda, determinados tipos de discursos que encontram-se fora do escopo de proteção da liberdade de expressão; é o caso, por exemplo, do discurso que incita a violência (fighting words) ${ }^{114}$ e da pornografia infantil ${ }^{115}$. A maior parte dos casos, porém, envolvem discurso de menor valor (low value speech), recebendo menor proteção da liberdade de expressão. Para cada categoria, a Suprema Corte criou testes e parâmetros para avaliar sua compatibilidade constitucional com a Primeira Emenda. O presente tópico tratará de apresentar, brevemente, alguns dos parâmetros criados.

1) Discurso subversivo - Ao início do século XX, a avaliação do discurso subversivo - i.e., aquele dirigido

111 SULLIVAN, Kathleen M. Post-liberal judging: the roles of categorization and balancing. University of Colorado Law Review, Denver, v. 63, p. 293, n. 3, 1992: "Categorization and balancing each employ quite different rhetoric. Categorization is the taxonomist's style-a job of classification and labeling. When categorical formulas operate, all the important work in litigation is done at the outset. Once the relevant right and mode of infringement have been described, the outcome follows, without any explicit judicial balancing of the claimed right against the government's justification for the infringement. Balancing is more like grocer's work (or Justice's)-the judge's job is to place competing rights and interests on a scale and weigh them against each other.Here the outcome is not determined at the outset, but depends on the relative strength of a multitude of factors".

112 FARBER, Daniel A. The categorical approach to protecting speech in American Constitutional Law. Indiana Law Journal, Bloomington, v. 84, p. 919, Verão 2009.

113 FARBER, Daniel A. The categorical approach to protecting speech in American Constitutional Law. Indiana Law Journal, Bloomington, v. 84, p. 917, Verão 2009.

114 Chaplinsky v. New Hampshire, 315 U.S. 568 (1942). O discurso que incita a violência não deve ser confundido com discurso subversivo e discurso do ódio, que, como se verá, recebem proteção especial da Suprema Corte. diretamente contra o governo, conclamando a sua derrubada - representou o primeiro grande desafio da Primeira Emenda para a Suprema Corte dos EUA ${ }^{116}$. Em 1917, em meio à Primeira Guerra Mundial, o Congresso norte-americano aprovou o Espionage Act, que criminava de forma rigorosa, durante o período de guerra, tentativas de insubordinação e insurreição contra o governo. Em Schenck v. United States (1919), a Corte manteve a condenação de um homem que distribuiu panfletos subversivos, afirmando a constitucionalidade do Espionage Act ${ }^{117}$. Escrevendo para um tribunal unânime, o Justice Oliver Wendell Holmes formulou o famoso critério para avaliar a possibilidade do discurso subversivo: o perigo real e iminente (clear and present danger) que aquele discurso causa à manutenção do governo ${ }^{118}$. Com fundamento em tal critério, a partir de Abrams v. United States (1919), o Justice Holmes, acompanhado do Justice Brandeis, deixando de identificar a presença do clear and present danger, começa a fortemente divergir da orientação da Corte para afirmar a inconstitucionalidade do Espionage Act em determinados $\operatorname{casos}^{119}$. Demoraram ainda muitos anos para a Suprema Corte abraçar o teste do clear and present danger, tendo uma postura mais favorável à liberdade de expressão somente se firmado após a Segunda Guerra Mundial; em Terminiello v. City of Chicago, o Justice Douglas, escrevendo pela maioria da Corte, afirmou que a intenção da Primeira Emenda era precisamente "convidar à disputa”, "induzir a uma condição de desassossego, criar insatisfação com a situação atual, ou mesmo agitar as pessoas para a ira", somente podendo ser limitada quando identificado o perigo real e iminente $\mathrm{e}^{120}$.

A doutrina do clear and present danger, contudo, passou a enfrentar uma nova ameaça a partir da década de 50: a "Ameaça Vermelha" e o marcatismo, marcados por uma forte repressão a pessoas e discursos identificados com o comunismo. Em Dennis v. United States

116 Embora o século XIX tenha convivido também com a repressão e supressão de discursos, a jurisprudência da Suprema Corte em matéria de liberdade de expressão é inexistente. V. FARBER, Daniel A. The First Amendment. 3. ed. New York: Thomsom Reuters/Foundation Press, 2010. p. 58.

117 Schenck v. United States, 249 U.S. 47 (1919).

118 Schenck v. United States, 249 U.S. 47 (1919): "The question in every case is whether the words used are used in such circumstances and are of such a nature as to create a clear and present danger that they will bring about the substantive evils that Congress has a right to prevent".

119 Abrams v. United States, 250 U.S. 616 (1919).

120 Terminiello v. City of Chicago, 337 U.S. 1 (1949). 
(1951), a Suprema Corte validou o Smith Act, nova lei editada para criminalizar discursos (inclusive meramente teóricos e acadêmicos) que pudessem implicar a subversão do regime de governo norte-americano ${ }^{121}$. Somente alguns anos depois, em Yates v. United States (1957), a Corte, aplicando a doutrina do clear and present danger, afastou a possibilidade de condenação em caso havendo a mera divulgação abstrata de ideias comunistas ${ }^{122}$. Da mesma forma, em Noto v. United States (1961), a Corte afirmou que a mera filiação ao Partido Comunista não poderia ensejar uma condenação criminal ${ }^{123}$.

Após a reafirmação do teste do clear and present danger pela Suprema Corte ${ }^{124}$, o teste para a avaliação constitucional do discurso subversivo foi sedimentado pelo tribunal em Brandenburg v. Ohio (1969), um dos principais julgados da Corte em matéria de discurso do ódio (hate speech). Ao afastar a condenação de um membro do Ku Klux Klan que advogava publicamente a utilização de violência física contra negros e judeus, a Corte definiu que o discurso subversivo somente pode ser proibido quando (i) é dirigido diretamente para incitar ações ilegais e (ii) quando é possível que tais ações aconteçam ${ }^{125}$. O teste de Brandenburg, por ter sido o primeiro a ser firmado pela Corte no seu processo de categorização, serviu de paradigma para os demais testes aplicáveis em outras categorias de expressão, além de ter funcionado como um paradigma para a ampla proteção da liberdade de expressão em outras hipóteses - afinal, nesses casos o interesse estatal em restringir o discurso é muito maior que em outros casos, tais como envolvendo discurso comercial e obscenidade (tópicos seguintes) ${ }^{126}$.

2) Discurso comercial - Durante muito tempo, a Suprema Corte afirmou que o discurso comercial (i.e., propagandas comerciais e peças publicitárias) encontrava-se fora do escopo da Primeira Emenda ${ }^{127}$. A virada desse entendimento deu-se, apenas, em caso de $1976^{128}$,

121 Dennis v. United States, 341 U.S. 494 (1951).

122 Yates v. United States, 354 U.S. 298 (1957).

123 Noto v. United States, 367 U.S. 290 (1961).

124 Em um dos casos, Watts v. United States (1969), a Suprema Corte afastou a condenação de um homem que havia ameaçado matar o Presidente, afirmando tratar-se apenas de uma "hipérbole política", sem risco real.

125 Brandenburg v. Ohio, 395 U.S. 444 (1969)

126 FARBER, Daniel A. The First Amendment. 3. ed. New York: Thomsom Reuters/Foundation Press, 2010. p. 76-77.

127 Valentine v. Chrestensen, 316 U.S. 52 (1942).

128 Virginia State Board of Farmacy v. Virginia Citizens Consumer Council, 425 U.S. 748 (1976). em que a Suprema Corte assentou que a proibição sobre a divulgação e publicidade de preço de medicamentos era inconstitucional frente à Primeira Emenda, sob a premissa de que a livre circulação de bens era também um interesse comercial relevante, além de que a propaganda comercial também serviria ao princípio democrático. A despeito disso, a própria Corte deixou claro que ao discurso comercial não deveria ser atribuído o mesmo patamar de proteção conferido a outros tipos de discursos. Os parâmetros para a avaliação de casos envolvendo propaganda comercial vieram a ser definidos em Central Hudson Gas \& Eletric. Corp. v. Public Service Comission (Central Hudson test). No teste de quatro etapas, o Judiciário deve averiguar (i) se a expressão comercial é lícita e não enganosa, (ii) se o interesse governamental em regular ou restringir a publicidade é substancial, (iii) se a finalidade buscada com tal regulação é alcançada e (iv) se a restrição não é mais ampla do que o necessário para atingir a mesma finalidade ${ }^{129}$.

3) Obscenidade - Tal como a publicidade comercial, por muito tempo a Suprema Corte considerou que o discurso obsceno (geralmente aquele que contêm material pornográfico explícito) não estaria protegido pela Primeira Emenda. Em Roth v. United States (1957), a maioria da Corte concluiu que material obsceno não era passível de proteção pela liberdade de expressão ${ }^{130}$. Partindo de uma perspectiva história, o voto condutor do Justice Brennan afirma que a Primeira Emenda "foi desenhada para assegurar o livre câmbio de ideias sobre mudanças políticas e sociais", estando implícito que a obscenidade seria uma forma de expressão "sem importância social"131. A despeito disso, mesmo em Roth e depois no caso Memoirs v. Massachusetts (1966), a Corte chegou a admitir a possibilidade de limites estatais à restrição da obscenidade, ensaiando um teste para aferir sua consti-

129 Central Hudson Gas \& Eletric. Corp. v. Public Service Comission, 447 U.S. 557 (1980).

130 Roth v. United States, 354 U.S. 476 (1957).

131 Roth v. United States, 354 U.S. 476 (1957): "(b) The protection given speech and press was fashioned to assure unfettered interchange of ideas for the bringing about of political and social changes desired by the people. (c) All ideas having even the slightest redeeming social importance - unorthodox ideas, controversial ideas, even ideas hateful to the prevailing climate of opinion - have the full protection of the guaranties, unless excludable because they encroach upon the limited area of more important interests; but implicit in the history of the First Amendment is the rejection of obscenity as utterly without redeeming social importance". 
tucionalidade $\mathrm{e}^{132}$. O teste afinal designado, e que sobrevive até hoje, foi construído em Miller v. California (1973) ${ }^{133}$.

Partindo de uma premissa muito mais restritiva de conteúdo do que em outras categorias - num caso julgado simultaneamente, o tribunal afirmou que materiais obscenos representam uma forma de "poluição" e "degradação", justificando sua supressão até mesmo contra adultos que tenham consentido com o seu uso ${ }^{134}$-, a Suprema Corte criou um teste em três etapas para verificar se um discurso é obsceno (e, portanto, fora do escopo de proteção da Primeira Emenda): (i) se uma pessoa comum, aplicando parâmetros comunitários contemporâneos, iria achar que aquela forma de expressão serve a um interesse puramente lascivo; (ii) se a expressão demonstra ou descreve, de uma forma patentemente ofensiva, uma conduta sexual definida pela lei; e (iii) se a expressão como um todo não contêm um conteúdo literário, artístico, político ou científico ${ }^{135}$.

4) Difamação - A convivência da liberdade de expressão com leis que punem a difamação (por exemplo, violação da honra, reputação e privacidade) é um dos episódios mais tradicionais de conflitos entre direitos fundamentais e de limites à proteção da liberdade de expressão (e, sobretudo, de imprensa). O caso paradigmático da Suprema Corte sobre a matéria é o New York Times Co. v. Sullivan (1964) ${ }^{136}$. Nesse caso, a Corte negou a possibilidade de indenização a agentes públicos que tinham sido alvo de um anúncio com informações falsas no The New York Times, sob o argumento de que o de-

\footnotetext{
Memoirs v. Massachusetts, 383 U.S. 413 (1966).
}

Miller v. California, 413 U.S. 15 (1973).

134 Paris Adult Theatre I v. Slaton, 413 U.S. 49 (1973): " (a) There is a proper state concern with safeguarding against crime and the other arguably ill effects of obscenity by prohibiting the public or commercial exhibition of obscene material. [...]. (d) Preventing the unlimited display of obscene material is not thought control. (e) Not all conduct directly involving 'consenting adults' only has a claim to constitutional protection".

135 Miller v. California, 413 U.S. 15 (1973): "The basic guidelines for the trier of fact must be: (a) whether "the average person, applying contemporary community standards" would find that the work, taken as a whole, appeals to the prurient interest, Roth, supra, at 489, (b) whether the work depicts or describes, in a patently offensive way, sexual conduct specifically defined by the applicable state law, and (c) whether the work, taken as a whole, lacks serious literary, artistic, political, or scientific value. If a state obscenity law is thus limited, First Amendment values are adequately protected by ultimate independent appellate review of constitutional claims when necessary". bate público deve ser necessariamente "ilimitado, robusto e aberto", e que as autoridades públicas poderiam estar sujeitas à ataques "veementes, cáusticos e algumas vezes indesejáveis”. Ao contrário de outras categorias protegidas pela Primeira Emenda, a Corte não formulou aqui um teste para verificar a possibilidade de proteção da liberdade de expressão, mas sim um parâmetro mais preciso: a prova da efetiva malícia na difamação (actual malice). Na prática, a Suprema Corte jogou para o ofendido (o autor numa ação de difamação) a necessidade de prova de que uma pessoa ou reportagem jornalística agiu de forma maliciosa ou temerária (reckless disresgard). O critério foi expandido em outros casos, sobretudo em Gertz v. Robert Welch, Inc. (1974), em que a Corte afirmou expressamente que o critério da actual malice aplica-se até mesmo para a proteção de notícias falsas ${ }^{137}$.

5) Discurso em locais públicos - Desde Hague v. CIO (1939), a Suprema Corte afirmou que a liberdade de expressão nas ruas e em parques deve ser a mais ampla possível, inadmitindo restrições que pudessem limitá-la substancialmente ${ }^{138}$. Em casos como Ward (v. supra) e Grayned v. Rockford (1972), contudo, a Corte afirmou que não se trata de uma garantia absoluta, sendo legítima a restrição de demonstrações musicais (em Ward) ou em determinados locais (como escolas) ${ }^{139}$, tendo em vista o legítimo interesse estatal na restrição. Os critérios orientadores dos limites de tais restrições vieram a ser delimitados em Perry Education Association v. Perry Local Educators Association $(1983)^{140}$. Em Perry, a Corte fixou a possibilidade de restrição à liberdade de expressão em locais públicos distinguindo-se entre três tipos de locais públicos: (i) o fórum público tradicional, que inclui ruas e parques, somente admitindo-se restrições incidental de tempo, local e modo; (ii) o fórum público limitado, que é aquele em que não necessariamente há ampla liberdade de expressão, mas, uma vez que o Estado tenha aberto para comunicação, deve ser considerado um fórum público; e (iii) o fórum não-público, tais como prédios públicos em que há limite de acesso, em que há ampla

137 Gertz v. Robert Welch, Inc., 418 U.S. 323 (1974): "Under the First Amendment there is no such thing as a false idea. However pernicious an opinion may seem, we depend for its correction not on the conscience of judges and juries but on the competition of other ideas".

138 Hague v. Committee for Industrial Organization, 307 U.S. 496 (1939).

139 Grayned v. City of Rockford, 408 U.S. 104 (1972).

140 Perry Education Association v. Perry Local Educators Association, 460 U.S. 37 (1983). 
possibilidade de restrição de liberdade de expressão e manifestação, inclusive quanto ao conteúdo.

$\mathrm{O}$ resultado desses critérios, considerados em conjunto com os critérios gerais de restrição de conteúdo, além dos parâmetros paralelos, resultam num intricado e complexo regime da liberdade de expressão no direito norte-americano. Naturalmente, e como é intuitivo, cada um desses parâmetros (sejam os gerais, ou também os específicos) levantam questionamentos e complexidades próprias. Mas o sistema todo, da maneira como desenhado ao longo dos anos pela jurisprudência, pode representar por si só um problema. Afinal, toda essa construção - muitas vezes confusa e assistemática - efetivamente produz os melhores resultados? O próximo tópico passa a tratar de algumas das críticas realizadas pela doutrina norte-americana ao cenário descrito acima. Ao final, contudo, a proposta é esse sistema possa inspirar o direito brasileiro, em que parâmetros e orientações gerais também possam ser oferecidos ao intérprete para avaliar casos envolvendo liberdade de expressão.

\section{Lições para o cenário brasileiro: racionaliza- ção da avaliação da liberdade de expressão}

Ao escrever sobre a jurisprudência da Suprema Corte em matéria de liberdade de expressão, Frederick Schauer começa um trabalho lembrando que "a essência da crítica constitucional consiste em ser gentil com seus colegas e deseducado com a Suprema Corte". O autor lembra então que esse papel vem sendo exercido por diversos comentadores das decisões da Corte acerca da Primeira Emenda ${ }^{141}$. As críticas podem se dirigir aos parâmetros específicos identificados pela Suprema Corte em cada caso, ou, de modo mais genérico, à própria sistemática de análise da liberdade de expressão construída pela Corte - notadamente, as diferenças quanto às restrições de conteúdo e entre discursos protegidos e de menor valor. As primeiras, por serem variadas e envolverem cenários específicos, não serão objeto do presente trabalho, que pretende focar mais na figura maior.

Em seu trabalho seminal sobre a Primeira Emenda, Steven Shiffrin já denunciava o que chamou de enge-

$141 \quad$ SCHAUER, Frederick. Speech and 'speech'- obscenity and 'abscenity: an exercise in the interpretation o constitutional language. Washington, The Georgetown Law Journal, v. 67, p. 899, 1979: "A colleague of mine has observed that the essence of constitutional criticism consists of being 'kind to your colleagues and unkind to the Supreme Court"'. nharia social na liberdade de expressão $0^{142}$, referindo-se à complexa construção da Suprema Corte em separar diferentes categorias de discursos e avaliar restrições de acordo com a sua neutralidade de conteúdo ou não. Opondo-se à visão tradicional de que tais parâmetros promovem uma "fortaleza teórica" para a liberdade de expressão, evitando que ela seja decidida caso a caso de acordo com a pressão e o interesse governamental ${ }^{143}$, o autor afirma que a teoria envolvendo a Primeira Emenda "na melhor das hipóteses precisa de uma séria explicação unificadora" e "na pior das hipóteses é ad hoc, sem princípios orientadores e caótica"144.

O autor passa, então, a insurgir-se contra o critério geral escolhido pela Corte para a avaliação da Primeira Emenda: a desconfiança com as restrições de conteúdo. Segundo Shifrrin, a ideia de que o Estado não deve regular o conteúdo é incompatível com a sua própria função: o governo faz escolhas de conteúdo corriqueiramente, como parte de sua atividade ${ }^{145}$. Mais do que isso, a distinção entre discursos de maior e menor valor envolvem, inegavelmente, uma escolha de conteúdo por parte da Suprema Corte ${ }^{146}$. O resultado dessa construção - desencontrada das próprias razões que justificam a proteção da liberdade de expressão - é que a própria Suprema Corte parece, em alguns casos, fugir de sua orientação; "os parâmetros de avaliação não vinculam aqueles que não querem ser vinculados e fazem pouco para guiar aquelas que desejam ser guiados" ${ }^{147}$.

Isto é: os parâmetros criados pela Corte, ao ten-

${ }_{142}$ SHIFRRIN, Steven H. The First Amendment, democracy and romance. Princeton: Princeton University Press, 1990. p. 9 e ss.

143 SHIFRRIN, Steven H. The First Amendment, democracy and romance. Princeton: Princeton University Press, 1990. p. 4.

144 SHIFRRIN, Steven H. The First Amendment, democracy and romance. Princeton: Princeton University Press, 1990. p. 4. (tradução livre).

145 SHIFRRIN, Steven H. The First Amendment, democracy and romance. Princeton: Princeton University Press, 1990. p. 20-21: "[...] [T] he claim that government, under the first amendment, can bear no animus toward any particular point of view is itself overbroad. [...] [F]rom the perspective of the government there's no 'equality of status in the field of ideas'. Government plays an enormous role in the intellectual marketplace".

146 SHIFRRIN, Steven H. The First Amendment, democracy and romance. Princeton: Princeton University Press, 1990. p. 22-23.

147 SHIFRRIN, Steven H. The First Amendment, democracy and romance. Princeton: Princeton University Press, 1990. p. 32 (tradução livre). 
tar estabelecer uma sistemática uniforme e organizada da liberdade de expressão, pouco ajudariam no papel de orientar os tribunais inferiores e evitar o decisionismo e a discricionariedade na avaliação da Primeira Emenda. Para o autor, os parâmetros da Corte padecem de excesso de confiança e cinismo. O primeiro decorre do fato de que tais princípios orientadores não conseguem abarcar todas as situações reais e casos concretos, resultando em simplificações que pouco orientam o intérprete. $\mathrm{O}$ cinismo é a possível utilização de tais parâmetros para mascarar e legitimar decisões discricionárias através de critérios pretensamente técnicos e neutros ${ }^{148}$.

Por outro lado, uma defesa tradicional da criação de parâmetros em matéria de liberdade de expressão - e, especialmente, da categorização realizada pela Suprema Corte - é empreendida por Frederick Schauer ${ }^{149}$. O autor lembra que, no campo da liberdade de expressão, o papel didático desempenhado pela Suprema Corte, de criar sistemas de regras e princípios para orientar os demais juízes e poderes, é relativamente baixo: a grande variedade de formas de expressão e restrições possíveis tornaria o sistema complexo demais para exercer uma função educadora. Nesse cenário, a jurisprudência deve guiar-se por princípios e parâmetros gerais e abertos, aptos a orientar o intérprete e evitar o decisionismo puro ${ }^{150}$. Tal modelo, nem flexível demais para o juiz, nem rígido demais, apresentaria duas principais vantagens: (i) a previsibilidade e a diminuição da possibilidade de erro e (ii) o maior compromisso com os valores da Primeira Emenda.

Quanto ao primeiro, o autor lembra que a ausência de previsibilidade em matéria de liberdade de expressão cria, para o juiz, mais riscos de resultados extravagantes e, para os particulares, maior possibilidade de autocensura, uma vez que as pessoas não saberão, com antecedência, qual tipo de expressão estará protegida ou não. Da mesma forma, maior é a possibilidade de erro judicial, uma vez que o juiz está menos adstrito a regras previamente fixadas ${ }^{151}$. Quanto ao segundo fator - compromisso com

148 SHIFRRIN, Steven H. The First Amendment, democracy and romance. Princeton: Princeton University Press, 1990. p. 34-35.

149 SCHAUER, Frederick. Categories and the First Amendment: a play in three acts. Vanderbilt Law Review, Nashville, v. 34, p. 296, Abril 1981.

150 SCHAUER, Frederick. Categories and the First Amendment: a play in three acts. Vanderbilt Law Review, Nashville, v. 34, p. 306-307, Abril 1981. a Primeira Emenda -, Schauer reconhece apesar da ponderação pura e simples (sem parâmetros) estar frequentemente associada com uma visão de menor proteção à liberdade de expressão, não há uma causalidade entre os dois: a definição de parâmetros pode, em tese, enfraquecer a liberdade de expressão ${ }^{152}$. A despeito disso, o autor afirma que a aplicação de parâmetros permite a avaliação de valores de longo prazo que transcendem aos casos particulares, além de constrangerem as forças e pressões psicológicas que poderiam justificar uma restrição à liberdade de expressão num caso concreto. Nesse cenário, os parâmetros podem atuar como forma mais efetiva de proteção da liberdade de expressão ${ }^{153}$.

Uma outra defesa de parâmetros na jurisprudência da Primeira Emenda é feita por Vincent Blasi, ao tratar da perspectiva patológica da Primeira Emenda ${ }^{154}$. Para o autor, a jurisprudência acerca da liberdade de expressão deve ser moldada e reforçada para estar preparada para períodos de especial perigo aos valores democráticos. Nesses períodos de patologia institucional, ideias dissidentes, subversivas ou pouco ortodoxas tendem a ser menos toleradas ${ }^{155}$, ameaçando o núcleo de proteção da

ville, v. 34, p. 299, Abril 1981.

152 SCHAUER, Frederick. Categories and the First Amendment: a play in three acts. Vanderbilt Law Review, Nashville, v. 34, p. 302, Abril 1981.

153 SCHAUER, Frederick. Categories and the First Amendment: a play in three acts. Vanderbilt Law Review, Nashville, v. 34, p. 304, Abril 1981: "Freedom of speech is a longterm value not always fully appreciated in the case at hand. In order fully to accomodate this long-term interest, we must often make what at first sight appear to be discordant shortterm decisions. Moreover, as Professor Emerson has most notably reminded us, freedom of speech is a value that runs counter to many of our intuitions. Psychological forces, if there are such things, run in favor of suppression. In a particular case the asserted governmental interest will often look far more appealing or even compelling than the first amendment interest. As a result, it is not at all surprising that discretion-limiting rules have traditionally provided far more in the way of first amendment protection than has particularized balancing".

154 BLASI, Vincent. The pathological perspective and the First Amendment. Columbia Law Review, New York, v. 85, p. 449-513, Abril 1985.

155 BLASI, Vincent. The pathological perspective and the First Amendment. Columbia Law Review, New York, v. 85, p. 450, Abril 1985: "The central empirical proposition of my thesis is that certain segments of time are of special significance for the preservation of the basic liberties of expression and inquiry because the most serious threats to those liberties tend to be concentrated in abnormal periods. [...] 'Pathology' in the sense I use the rerm is a social phenomenon, characterized by a notable shift in attitudes regarding the tolerance of unorthodox ideas. What makes a period ment: a play in three acts. Vanderbilt Law Review, Nash- 
Primeira Emenda ${ }^{156}$. Assim, a jurisprudência acerca da liberdade de expressão deve ser pensada de forma a garantir a sobrevivência da livre circulação de ideias mesmo em tempos conturbados. Como expõe o autor, essa visão decorre da própria concepção de constitucionalismo: resguardar, por meio de cláusulas rígidas e que não estejam à disposição das maiorias eventuais, determinados valores que são considerados importantes ${ }^{157}$. O mesmo ocorre com a liberdade de expressão; no mais das vezes, ela não será especialmente desafiada. No entanto, é preciso construir um arsenal teórico apto a entrincheirar os valores que a sustentam justamente quanto estes sejam ameaça$\operatorname{dos}^{158}$. Um desses mecanismos é a instituição de preceitos, princípios e parâmetros que deixem pouco espaço para a discricionariedade judicial futura, diminuindo a incerteza de aplicação das normas relativas à liberdade de expressão ${ }^{159}$.

Por fim, vale mencionar a posição pragmática adotada por Richard Posner na avaliação da liberdade de expressão ${ }^{160}$. A versão tradicional defendida por Posner ${ }^{161}$ tende a favorecer, contrariamente à jurisprudência da Su-

pathological is the existence of certain dynamics that radically increase the likelihood that people who hold unorthodox views will be punished for what they say or believe".

156 BLASI, Vincent. The pathological perspective and the First Amendment. Columbia Law Review, New York, v. 85, p. 462, Abril 1985.

157 BLASI, Vincent. The pathological perspective and the First Amendment. Columbia Law Review, New York, v. 85, p. 453-454, Abril 1985: "[...] [A]ll plausible objectives of constitutionalism depend for their realization on the existence of a considerable measure of continuity and stability regarding the most basic structural arrangements and value commitments of the constitutional regime. The reason for this convergence lies in the fact that all objectives of constitutionalism by definition share a common feature: the goal of limiting present exercises of political power by resort to some notion of superior authority. [...] Whether constitutional provisions are invoked to protect political minorities, break political deadlocks, raise the level of public debate to a more idealistic plane, or serve any of the other possible objectives of constitutionalism, the relative continuity and stability of the constitutional tradition is likely to have a major impact on the success of the endeavor".

158 BLASI, Vincent. The pathological perspective and the First Amendment. Columbia Law Review, New York, v. 85, p. 456-458, Abril 1985.

159 BLASI, Vincent. The pathological perspective and the First Amendment. Columbia Law Review, New York, v. 85, p. 472-474, Abril 1985.

160 POSNER, Richard A. Pragmatism versus purposivism in First Amendment analysis. Stanford Law Review, Stanford, v. 54, p. 737-752, Abril 2002.

161 POSNER, Richard A. Free speech in a economic perspective. Suffolk University Law Review, Boston, v. 20, p. 1-54 Primavera 1986. prema Corte, uma análise ponderativa em que o intérprete deve avaliar os custos e benefícios na manutenção da liberdade de expressão - quando os custos superarem os benefícios (por exemplo, porque produz consequências danosas), o julgador poderá decidir pela supressão do discurso. A despeito dessa posição, o autor reconhece que os casos envolvendo liberdade de expressão geralmente apresentam mais custos do que benefícios; é muito fácil as pessoas ficarem ofendidas com a liberdade de expressão, e as vantagens da sua garantia parecem para o julgador muito remotas e indiretas ${ }^{162}$. Dessa forma, mesmo a perspectiva pragmática reconhece que o julgador não deve ter "carta branca" para avaliar casos de liberdade de expressão, e que um sistema de parâmetros mais precisos é preferível e mais seguro para a sua garantia ${ }^{163}$. Embora faça essa "concessão" à sua posição original, Posner não deixa de lembrar o fato de que tais parâmetros não impediram a Suprema Corte de agir de forma discricionária ${ }^{164}$.

Em resumo: fatores como (i) a preocupação com uma maior previsibilidade nos casos envolvendo a liberdade de expressão, garantindo maior segurança aos particulares e ao governo ao lidarem com diferentes tipos de discursos; (ii) o reforço dos valores da liberdade de expressão para períodos especialmente conturbados e menos tolerantes; e (iii) a fuga de decisionismo que, avaliando apenas o caso concreto, pudesse prejudicar a liberdade de expressão no longo prazo, parecem ser os elementos comuns das posições que sustentam a utilização de testes e parâmetros para avaliar os casos envolvendo a Primeira Emenda - sem desconsiderar, naturalmente, as críticas formuladas aos parâmetros formulados pela Suprema

162 POSNER, Richard A. Pragmatism versus purposivism in First Amendment analysis. Stanford Law Review, Stanford, v. 54, p. 744, Abril 2002: "What is true, and is a shortcoming of the pragmatic approach, is that the costs of freedom of expression are often more salient than the benefits, and their salience may cause the balance to shift too far toward suppression. People are often deeply offended by hearing their religious, moral, political, or even aesthetic beliefs challenged; and offense is a cost. [...] And because the cost of heterodox speech is immediate and its benefit deferred, the benefit may be slighted. All this must be kept steadily in mind by judges called upon to uphold the suppression of expression in the name of protecting people from being offended".

163 POSNER, Richard A. Pragmatism versus purposivism in First Amendment analysis. Stanford Law Review, Stanford, v. 54, p. 745, Abril 2002.

164 POSNER, Richard A. Pragmatism versus purposivism in First Amendment analysis. Stanford Law Review, Stanford, v. 54, p. 755-756, Abril 2002. 
Corte. Como destaca Eric Barendt, a base da jurisprudência da Suprema Corte sobre a matéria parece ser fruto da vontade de criar uma presunção favorável à liberdade de expressão no processo ponderativo, bem como da desconfiança dos interesses governamentais na supressão da expressão, e das decisões dos tribunais inferiores ${ }^{165}$.

Nesse cenário, a jurisprudência dos Estados Unidos foge bastante do contexto de outros tribunais também com decisões bastante expressivas em matéria de liberdade de expressão, tais como a Suprema Corte do Canadá e o Tribunal Constitucional da Alemanha, que avaliam os casos aplicando o princípio da proporcionalidade de forma muito próxima com a que também se consagrou nos últimos anos no direito brasileiro ${ }^{166}$. Nada obstante, se não é possível (nem conveniente) importar o modelo decisório dos Estados Unidos sobre a liberdade de expressão, tampouco seria conformar-se com o atual modelo brasileiro, identificado na introdução, em que a avaliação da liberdade de expressão é feita, no mais das vezes, com fundamento tão somente nos dispositivos vagos da Constituição que tratam do tema. O modelo atualmente vigente não precisa, contudo, ser abandonado; o uso da técnica da ponderação e da proporcionalidade foi amplamente consagrada pela doutrina e jurisprudência $^{167}$, sendo também utilizada para a avaliação da liberdade de expressão em diversos tribunais pelo mundo ${ }^{168}$. A racionalização da atividade jurisdicional não implica o desprezo de tais métodos, mas no seu aperfeiçoamento. Isso passa pela utilização da técnica da ponderação tendo

165 BARENDT, Eric. Freedom of speech. 2. ed. Oxford: Oxford University Press, 2007. p. 51: "All these principles are designed to give speech more protection than it would enjoy if courts treated it and competing interests as factor of equal weight or importance in the balancing process. There is a strong presumption in favour of free speech", e p. 53: "Much of it [the U.S. jurisprudence] is explicable in terms of a strong suspicion of government, and its motives for imposing restrictions on speech. The principles formulated by the Supreme Court also appear to reveal a distrust of lower state courts [...]".

166 BARENDT, Eric. Freedom of speech. 2. ed. Oxford: Oxford University Press, 2007. p. 57-63.

167 O novo Código de Processo Civil (Lei no 13.105/2015) faz expressa referência à utilização da ponderação como técnica de decidir no caso de conflito entre normas, exigindo a fundamentação pelo magistrado (art. $489, \$ 2^{\circ}$ : "No caso de colisão entre normas, o juiz deve justificar o objeto e os critérios gerais da ponderação efetuada, enunciando as razões que autorizam a interferência na norma afastada e as premissas fáticas que fundamentam a conclusão").

168 BARENDT, Eric. Freedom of speech. 2. ed. Oxford: Oxford University Press, 2007. p. 51. em vista não apenas o caso concreto, mas outros casos similares (pretensão de universalidade) ${ }^{169}$, bem como a criação de orientações e parâmetros que possam guiar o intérprete ao julgar casos futuros ${ }^{170}$. Nesse cenário, “não será mais o caso de uma simples ponderação ad hoc, na qual o juiz conta apenas com seu próprio bom senso para solucionar o conflito; ao contrário, haverá um conjunto importante de standards públicos à sua disposição"171.

No caso da liberdade de expressão, essa racionalização, por meio de parâmetros e testes decisórios, apresenta três principais vantagens já antecipadas anteriormente. Em primeiro lugar, tal visão permitiria que o impacto das decisões judiciais na liberdade de expressão seja avaliado de forma mais geral, e não tão somente em relação ao caso concreto submetido ao juiz. Como se viu, ao julgar um caso por vez, o intérprete não tenderá a avaliar o impacto geral na liberdade de expressão; o impacto individual, de fato, é muitas vezes pequeno. Uma indenização concedida num determinado caso, ou a proibição de determinado tipo de manifestação noutro não produzirão um estado de inconstitucionalidade que vulnere a proteção da livre expressão na Constituição Federal. Uma sequência de decisões nessa linha, por sua vez, tenderá a criar um contínuo impacto que transcende os casos individuais, criando uma percepção negativa da proteção à liberdade de expressão. A construção de determinados parâmetros permite ao intérprete fugir às particularidades dos casos individuais e construir uma teoria de garan-

169 BARCELLOS, Ana Paula de. Ponderação, racionalidade e atividade jurisdicional. Rio de Janeiro: Renovar, 2005. p. 130-132: "A solução a que chega o intérprete deve ser generalizada para todas as outras situações semelhantes ou equiparáveis, e, para isso, deve ser submetida ao teste da universalização: é possível e adequado aplicar a decisão a que se chegou a todos os casos similares? Essa exigência decorre naturalmente do dever de isonomia aplicado à prestação da jurisdição, pelo qual todos aqueles que se encontrem em situação equivalente devem receber a mesma resposta do Poder Judiciário".

170 BARCELLOS, Ana Paula de. Ponderação, racionalidade e atividade jurisdicional. Rio de Janeiro: Renovar, 2005. p. 145: "É perfeitamente possível e desejável, por meio da reflexão abstrata e/ou do estudo e tabulação dos precedentes judiciais, que a doutrina se ocupe de construir os sentidos próprios de cada direito, propondo parâmetros ou standards específicos capazes de identificar o que deve ser considerado como prerrogativa essencial de cada direito, o que pode sofrer restrição, em que circunstâncias isso pode acontecer, dentre outros elementos necessário para a compreensão mais precisa dos direitos.

171 BARCELLOS, Ana Paula de. Ponderação, racionalidade e atividade jurisdicional. Rio de Janeiro: Renovar, 2005. p. 150-152. 
tia da liberdade de expressão que atente ao seu impacto como um todo no cenário jurídico brasileiro.

Desse ponto decorre, em segundo lugar, que os parâmetros especialmente pensados para a proteção da liberdade de expressão poderão criar uma presunção a seu favor que tornará mais difícil do julgador afastá-la no caso concreto. É o caso, por exemplo, da doutrina do clear and present danger ou da actual malice da Suprema Corte dos EUA; partindo-se de uma presunção favorável à liberdade de expressão, exige-se de um intérprete um esforço argumentativo muito maior para afastá-la ou relativizá-la no caso concreto. A jurisprudência de diversos países reconhece a liberdade de expressão como um direito preferencial, o que não significa que ela irá sempre prevalecer. Trata-se de parâmetros para avaliar os casos envolvendo a liberdade de expressão, e não de uma regra absoluta em seu favor. Quando ela deva ser afastada, contudo, o intérprete deverá demonstrar porque a preferência estabelecida pelo parâmetro deve ser ilidida naquela hipótese. A ideia é construir um case a favor da liberdade de expressão que garanta a sua proteção pelo menos na maior parte dos casos.

Essa justificativa está ainda relacionada com a perspectiva patológica apresentada acima no direito norte-americano: parâmetros favoráveis à garantia da liberdade de expressão tendem a construir uma fortaleza teórica de proteção apta a sustentá-la mesmo em tempos especialmente conturbados e de menor tolerância a certas ideias. Uma avaliação caso a caso, por sua vez, submete a avaliação da liberdade de expressão às pressões e rigores de cada tempo. Os valores do constitucionalismo - estabilidade institucional e garantia de determinados direitos mesmo contra as investidas das maiorias - aqui atuam em favor de um aparato jurídico apto a proteger as potenciais ameaças futuras à liberdade de expressão.

Em terceiro lugar, a presença de orientações que conduzam a atividade do intérprete ao avaliar a liberdade de expressão é um fator de segurança jurídica, tanto para o Poder Judiciário como para o Poder Público e os particulares. No que toca ao Poder Judiciário, premissas estabelecidas pelas instâncias superiores permitem o intérprete avaliar os casos a ele submetidos sem contar apenas com proposições legais abstratas no texto constitucional, garantindo ainda uma maior controlabilidade das decisões judiciais pelos tribunais, que poderão avaliar a correção das decisões de instâncias inferiores com menor grau de subjetividade. Esse cenário garante, assim, uma maior previsibilidade a orientar a atuação do Poder Público e dos particulares - ao editar ou regulamentar uma lei, premissas estabelecidas pelo Poder Judiciário permitem ao legislador ou administrador público avaliar se estão trabalhando no campo do constitucionalmente possível e adequado. Por sua vez, aos particulares - aí incluídos, por exemplo, os veículos de mídia - é possível avaliar com antecipação se determinados discursos ou formas de expressão são lícitos. Em relação a esse último aspecto, a indefinição jurídica é potencialmente prejudicial à liberdade de imprensa, criando o risco de que os veículos de comunicação possam deixar de veicular certas matérias pelo risco de processos ou represarias.

Em resumo: sem prejuízo das críticas aos critérios que foram construídos no direito norte-americano para avaliar casos envolvendo a Primeira Emenda, o estabelecimento de parâmetros e critérios para avaliar casos de liberdade de expressão apresentará vantagens ao cenário jurídico brasileiro, não apenas no que toca à previsibilidade da atuação jurisdicional, mas também no que diz respeito à própria proteção e garantia da liberdade de expressão como direito fundamental.

\section{Conclusão}

A racionalização proposta nas últimas páginas não envolve qualquer tipo de novidade. A orientação da atividade judicial por meio de parâmetros e premissas previamente estabelecidas é antiga e encontra-se no centro do debate entre maximalismo e minimalismo, aplicando-se para todos os campos do direito. A tese do presente trabalho é que a avaliação caso a caso, sem premissas mais ou menos objetivas, é prejudicial à liberdade de expressão, seja porque as narrativas individuais tendem a impressionar o intérprete a adotar medidas de supressão ou restrição da liberdade expressão, ou porque os casos individuais não permitem ao intérprete uma avaliação dos impactos em larga escala de uma decisão tomada em desfavor da liberdade de expressão.

O exemplo norte-americano aqui exposto parece representar o oposto do cenário brasileiro: uma sistematização intricada e complexa, com todos os elogios e críticas que daí podem decorrer. Diferenças substanciais não apenas no sistema jurídico, como também na tradição democrática e na própria forma de avaliação da liberdade de expressão não permitiriam que parâmetros similares fossem importados ao direito brasileiro. Naturalmente, ainda 
precisamos construir um entendimento sobre a liberdade de expressão no Brasil a partir dos nossos próprios anseios e circunstâncias ${ }^{172}$. A despeito disso, o modelo norte-americano, ao menos na sua visão geral - através do estabelecimento de parâmetros e testes para avaliar as restrições à liberdade de expressão - poderá atuar como inspiração para que nossas cortes levem a liberdade de expressão a sério; isso significa não apenas reconhecer o seu valor teórico, mas aplicá-la de forma coerente e consistente.

O direito, ao menos numa visão pós-positivista, jamais pode prescindir da razão, mas também não ignora a presença da sensibilidade: tratando-se afinal de um meio para a realização da justiça, não se pode deixar de exigir do intérprete a sensibilidade com as coisas humanas. A premissa do presente trabalho é de que, no momento e no que toca à liberdade de expressão, nossos tribunais estão bem mais pendentes à sensibilidade, lidando, sem maiores premissas, com conflitos entre direitos fundamentais e valores constitucionais de alta carga axiológica. A partir daí, a tese é essencialmente propositiva: a de que racionalizar a liberdade de expressão com parâmetros e testes poderá contribuir para valorizá-la a longo prazo. Fora dessa proposição, há, apenas, a esperança: de que o ideal da liberdade de expressão seja realmente abraçado para começar a discuti-lo para valer.

\section{Referências}

BARCELLOS, Ana Paula de. Ponderação, racionalidade e atividade jurisdicional. Rio de Janeiro: Renovar, 2005.

BARENDT, Eric. Freedom of speech. 2. ed. Oxford: Oxford University Press, 2007.

BHAGWAT, Ashutosh. The test that ate everything: intermediate scrutiny in First Amendment jurisprudence. University of Illinois Law Review, Chicago, v. 2007, n. 3, p. 786, 2007.

BLASI, Vincent. The pathological perspective and the

172 Nesse sentido, valem as advertências de PEREIRA, Jane Reis Gonçalves. Classificação indicativa e vinculação de horários na programação de TV: a força das imagens e o poder das palavras. Revista SJRJ, Rio de Janeiro, v. 20, n. 38, p. 175-176, dez. 2013: "A tradição filosófica dos Estados Unidos no domínio da liberdade de expressão é riquíssima e merece ser estudada e aproveitada. No entanto, deve-se ter cautela ao transpor para o Brasil um arsenal de argumentos formulados em um contexto muito diverso do nosso, deixando de lado os pontos em que nossa Constituição se diferencia radicalmente do modelo norte-americano. É importante olhar para fora, mas sem esquecer quem somos e onde estamos".
First Amendment. Columbia Law Review, New York, v. 85, p. 449-513, Abril 1985.

CHEQUER, Claudio. A liberdade de expressão como direito fundamental preferencial prima facie: análise crítica e proposta de revisão ao padrão jurisprudencial brasileiro. Rio de Janeiro: Lumen Juris, 2011.

ELY, John Hart. Democracia e desconfiança: uma teoria do controle judicial de constitucionalidade. São Paulo: M. Fontes, 2010.

FALLON JUNIOR., Richard H. Fact and fiction about facial challenges. California Law Review, Berkeley, v. 99, n. 4, p. 915-974, Agosto 2011.

FARBER, Daniel A. The categorical approach to protecting speech in American Constitutional Law. Indiana Law Journal, Bloomington, v. 84, p. 917-938, Verão 2009.

FARBER, Daniel A. The First Amendment. 3. ed. New York: Thomsom Reuters/Foundation Press, 2010.

FLEMING, James E. The Incredible Shrinking Constitutional Theory: from the oartial Constitution to the minimal Constitution. Fordham Law Review, New York, v. 75, p. 2.887, maio 2007 .

HEYMAN, Stephen J. Freedom of speech \& human dignity. New Haven: Yale University Press, 2008.

KAGAN, Elena. Private speech, public purpose: the role of governmental motive in first amendment doctrine. The University of Chicago Law Review, Chicago, v. 63, p. 413517, Primavera 1996.

MACDONALD, Barry. Speech and distrust: rethinking the content approach to protecting the freedom of expression. Notre Dame Law Review, Notre Dame, v. 81, p. 1.347-1430, Issue 4, 2006.

NIMMER, Melville B. The meaning of symbolic speech under the First Amendment. UCLA Law Review, Los Angeles, v. 21, p. 29-62, 1973

PEREIRA, Jane Reis Gonçalves. Classificação indicativa e vinculação de horários na programação de TV: a força das imagens e o poder das palavras. Revista SJRJ, Rio de Janeiro, v. 20, n. 38, p. 169-197, dez. 2013.

PEREIRA, Jane Reis Gonçalves. Interpretação constitucional e direitos fundamentais: uma contribuição ao estudo das restrições aos direitos fundamentais na perspectiva da teoria dos princípios. Rio de Janeiro: Renovar, 2006.

POSNER, Richard A. Free speech in a economic perspective. Suffolk University Law Review, Boston, v. 20, p. 1-54 Primavera 1986. 
POSNER, Richard A. Pragmatism versus purposivism in First Amendment analysis. Stanford Law Review, Stanford, v. 54, p. 737-752, abr. 2002.

RABACOV, Paula Chueke; LEITE, Fábio Oliveira. $L i-$ berdade de expressão e direitos da personalidade na jurisprudência do STJ. Disponível em: <http://www.puc-rio. br/pibic/relatorio_resumo2012/relatorios_pdf/ccs/DIR/ JUR-Paula\%20Chueke\%20Rabacov.pdf>. Acesso em: 22 mar. 2015.

SCHAUER, Frederick. Categories and the First Amendment: a play in three acts. Vanderbilt Law Review, Nashville, v. 34, p. 265-308, abr. 1981.

SCHAUER, Frederick. Speech and 'speech'- obscenity and 'abscenity: an exercise in the interpretation o constitutional language. Washington, The Georgetown Law Journal, v. 67, p. 899-933, 1979.

SCHLAG, Pierre J. Rules and standards. UCLA Law Review, Los Angeles, v. 33, p. 379-406, dez. 1985.

SCHREIBER, Simone. Liberdade de expressão: justificativa teórica e a doutrina da posição preferencial no ordenamento jurídico. In: BARROSO, Luís Roberto (Org.). A reconstrução democrática do direito público no Brasil. Rio de Janeiro: Renovar, 2007. p. 217-258.

SHIFRRIN, Steven H. The First Amendment, democracy and romance. Princeton: Princeton University Press, 1990.
SILVA, Alexandre Garrido da. Minimalismo, democracia e expertise: o Supremo Tribunal Federal diante de questões políticas e científicas complexas. Revista de Direito do Estado, Rio de Janeiro, n. 12, p. 116, out./dez. 2008

STONE, Geoffrey R. Content regulation and the First Amendment. Willian and Mary Law Review, Williamsburg, v. 25, n. 2, p. 189-252, Inverno 1983.

STONE, Geoffrey R. Restriction of speech because of its content: the peculiar case of subject-matter restrictions. The University of Chicago Law Review, Chicago, v. 46, Issue 1, p. 81-115, 1978.

SULLIVAN, Kathleen M. Post-liberal judging: the roles of categorization and balancing. University of Colorado Law Review, Denver, v. 63, n. 3, p. 293-317, 1992.

SULLIVAN, Kathleen M. The Supreme Court 1991 Term - Foreword: the justices of rules and standards. Harvard Law Review, Cambridge, v. 106, p. 22-123, jan. 1993.

SUNSTEIN, Cass. Beyond judicial minimalism. Preliminary draft 9/25/08. Harvard University Public Law and Legal Theory, Working Paper No. 08-40, Cambridge, p. 20, 2007.

SUNSTEIN, Cass. One case at a time: judicial minimalism on the Supreme Court. Cambridge: Harvard University Press, 2001.

SUNSTEIN, Cass. Second-order perfectionism. Public Law and Legal Theory Working Paper No. 144, Chicago, dez. 2006. 